\title{
Effects of the antimicrobial agent Triclosan on bacterial resistance to disinfection in wastewater treatment processes
}

Meilin Liu

West Virginia University

Follow this and additional works at: https://researchrepository.wvu.edu/etd

\section{Recommended Citation}

Liu, Meilin, "Effects of the antimicrobial agent Triclosan on bacterial resistance to disinfection in wastewater treatment processes" (2008). Graduate Theses, Dissertations, and Problem Reports. 2673. https://researchrepository.wvu.edu/etd/2673

This Thesis is protected by copyright and/or related rights. It has been brought to you by the The Research Repository @ WVU with permission from the rights-holder(s). You are free to use this Thesis in any way that is permitted by the copyright and related rights legislation that applies to your use. For other uses you must obtain permission from the rights-holder(s) directly, unless additional rights are indicated by a Creative Commons license in the record and/ or on the work itself. This Thesis has been accepted for inclusion in WVU Graduate Theses, Dissertations, and Problem Reports collection by an authorized administrator of The Research Repository @ WVU. For more information, please contact researchrepository@mail.wvu.edu. 


\title{
Effects of the Antimicrobial Agent Triclosan on Bacterial Resistance to Disinfection in Wastewater Treatment Processes
}

\section{Meilin Liu}

\author{
Thesis submitted to the \\ College of Engineering and Mineral Resources \\ at West Virginia University \\ in partial fulfillment of the requirements \\ for the degree of
}

Master of Science

in

Civil and Environmental Engineering

\author{
Benoit Van Aken, Ph.D., Chairperson \\ Jianbo Yao, Ph.D. \\ Lianshin Lin, Ph.D.
}

Department of Civil and Environmental Engineering

\author{
Morgantown, West Virginia
}

2008

Key words: Disinfection, Antimicrobial Resistance, Triclosan, Chlorination, Activated Sludge 


\title{
Abstract \\ Effects of the Antimicrobial Agent Triclosan on Bacterial Resistance to Disinfection in Wastewater Treatment Processes
}

\begin{abstract}
Meilin Liu
2-(2,5-Dichlorophenoxy)-5-chlorophenol or Triclosan is a widely used antimicrobial agent included in a multitude of products, such as soap, toothpaste, and personal care products.

The objective of this research was to investigate the effects of Triclosan on the resistance of activated sludge bacteria to conventional disinfection processes applied in wastewater treatment processes, such as chlorination and UV.

Specific Aim 1: A complex bacterial community collected from an active sludge was acclimated over several sub-cultures in the presence of different concentrations of Triclosan (from 0.0 to $20 \mathrm{mg} \mathrm{L}^{-1}$ ) and then exposed to sub-lethal doses of chlorine and UV irradiation. Determination of bacterial viability by direct counting and flow-cytometry showed that microbial communities exposed to Triclosan exhibited an increased susceptibility to chlorination and UV by comparison to non-exposed bacteria.
\end{abstract}

Specific Aim 2: In order to determine the origin of the change of susceptibility observed in Specific Aim 1, we characterized the microbial communities by construction of gene library and restriction fragment length polymorphism (RFLP). Results showed that acclimation on Triclosan resulted in a significant reduction of the bacterial diversity, suggesting that the change of susceptibility to disinfection could be explained, at least partly, by a change of the bacterial community structure. To investigate whether exposure to Triclosan could select bacterial species with a lower susceptibility to chlorination, two highly resistant strains were isolated from Triclosan-acclimated cultures and identified as Pseudomonas fluorescens and Serratia marcescens, which are opportunistic pathogens previously documented as highly resistant to Triclosan. This time, flow cytometry results showed that one of the strains, S. marcescens, exhibited a significant decrease of susceptibility to chlorination after acclimation in the presence of high concentration of Triclosan.

Specific Aim 3: In order to investigate further the relative susceptibility to chlorination of different species in Triclosan-exposed activated sludge bacteria, the microbial community structure was characterized by terminal-restriction fragment length polymorphism (T-RFLP) after sorting dead and living bacteria by flow-cytometry. Our preliminary results showed again that acclimation on Triclosan resulted in a significant reduction of the bacterial diversity, and, more importantly, that several species in Triclosan-acclimated bacterial suspensions exhibited a much higher resistance to chlorination.

Our results provide the first evidence that acclimation on sub-lethal doses of the antimicrobial agent Triclosan can result in decreasing susceptibility of opportunistic 
pathogens, which could have potential important implication for public health. In addition, our experiments combining flow-cytometry for dead-living bacteria sorting with T-RFLP for microbial community structure characterization opens the way for further research on the effect of antimicrobial agents on the relative susceptibility of different pathogens to disinfection systems. 


\section{Acknowledgements}

First of all, I wish to thank to my advisor Professor Benoit Van Aken for directing and advising me on my research work. I also wish to thank my committee members:

Professors Jianbo Yao and Lance Lin for their advices and help during my investigation and pre-defense.

Also I have tried to perform my research work using a large variety of molecular and analytical methods, and it would have been impossible for me to complete these works in these different fields without the kind assistance of people to whom I would like to express my gratitude: Kenneth Steward, for letting me use his HPLC analysis system, Kathy Brundage, who has kindly help me with flow-cytometry analyses, Danielle Ellis, for T-RFLP technology support, Professor Xinchao Wei, Will Ravenscroft, and Karen Buzby, who shared their equipment and experience with me.

Thank you all!

Meilin Liu,

November 2008 


\section{Table of Contents}

Chapter 1: Introduction .............................................................................................. 1

1.1 Emergent Contaminants and Pharmaceutical and Personal Care Products (PPCPs) 1

1.2 Wastewater treatment plants as potential reservoirs of antimicrobial resistance ...... 1

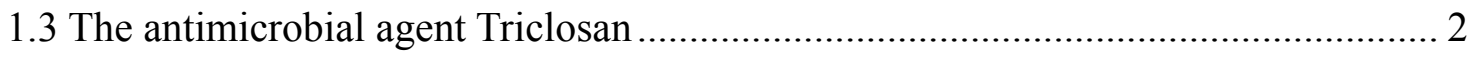

1.4 Relationship between Antimicrobial Agents and Disinfection................................. 3

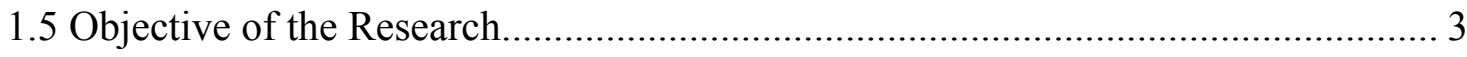

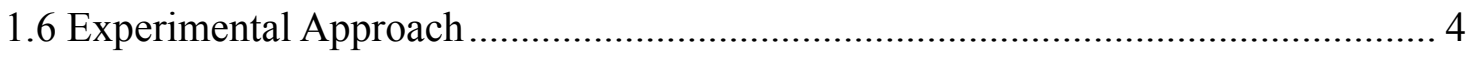

Chapter 2: Background and Literature Review ……………....................................... 5

2.1 Environmental Concerns of Emergent Contaminants and PPCPs ........................... 5

2.2 Biological Effects of Exposure to Antimicrobial Agent............................................ 6

2.2.1 Antimicrobial resistance mechanisms.......................................................... 6

2.2.2 Wastewater treatment plants as potential reservoirs of antimicrobial resistance 7

2.3 Relationship between Antimicrobial Agents and Disinfection................................ 8

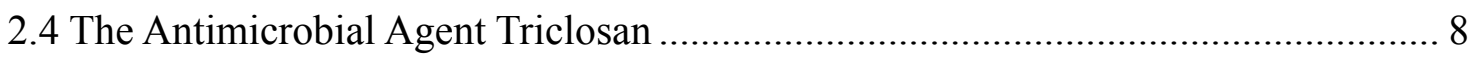

2.4.1 Generality of Triclosan ....................................................................... 8

2.4.2 Biological activity of Triclosan.................................................................... 9

2.4.3 Environmental concerns of Triclosan spread ………...................................... 10

2.4.3.1 Toxicity of Triclosan........................................................................... 10

2.4.3.2 Biodegradation resistance and by-products of Triclosan ........................... 10

2.4.3.3 Typical concentrations in WWTPS ......................................................... 11

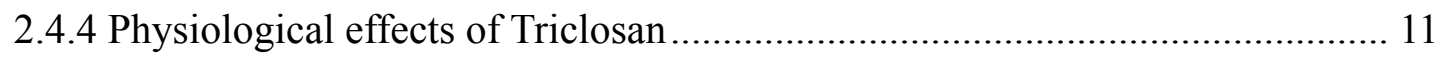

2.4.5 Relationship between Triclosan and development of antimicrobial resistance 12

2.5 Wastewater Treatment ................................................................................ 12

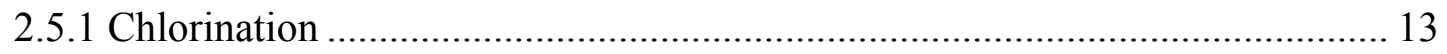

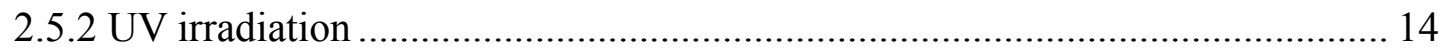

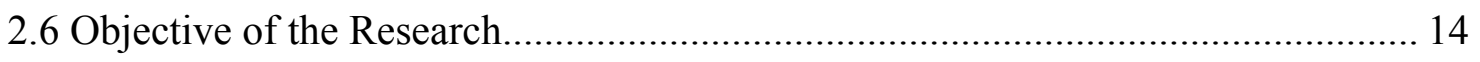

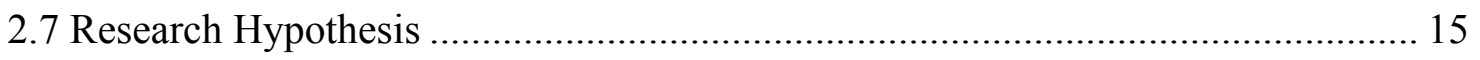

2.8 Overview of Terminal-restriction fragment length polymorphism and

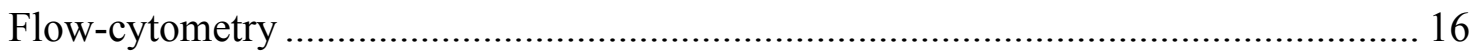

2.8.1 Terminal-restriction fragment length polymorphism (T-RFLP) analysis ......... 16

2.8.2 Flow-cytometry analysis and cell sorting ...................................................... 16

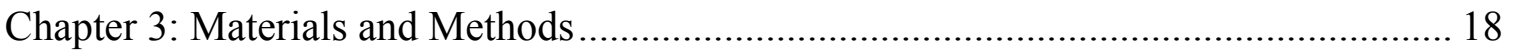

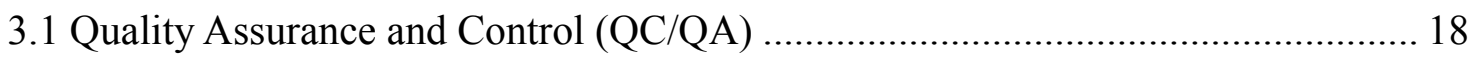

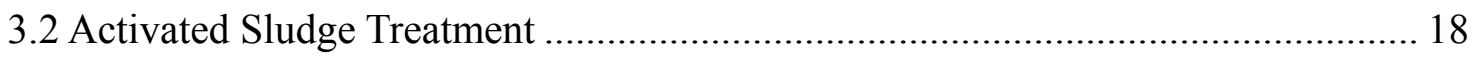

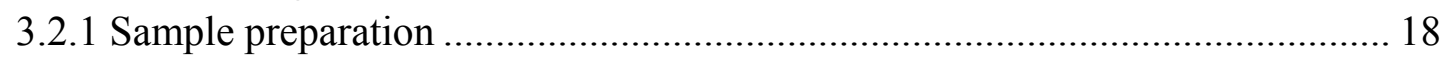

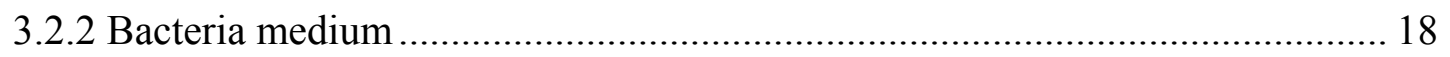

3.2.3 Preparation of activated sludge bacteria ........................................................ 19

3.2.4 Isolation of pure cultures from activated sludge mixture ………….................. 19

3.2.5 Culture growth and exposure to Triclosan (mix cultures and pure cultures) .... 19

3.2.6 Preparation of resting cells........................................................................ 20 


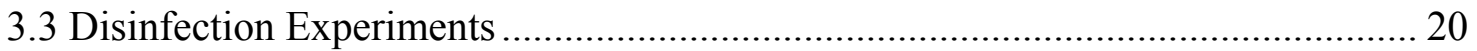

3.3.1 Chlorination of Triclosan acclimated bacteria ................................................ 20

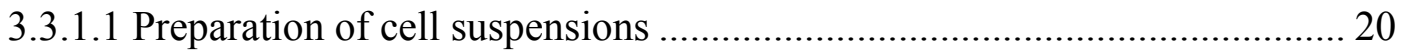

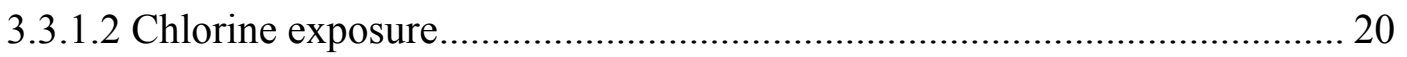

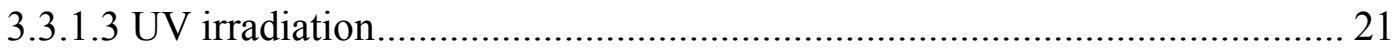

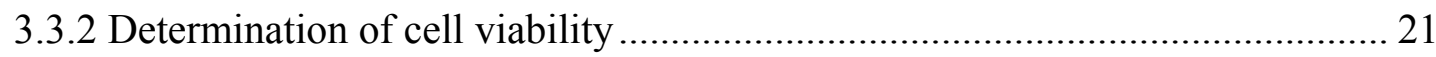

3.3.2.1 Colony forming units (CFU) counting .................................................... 22

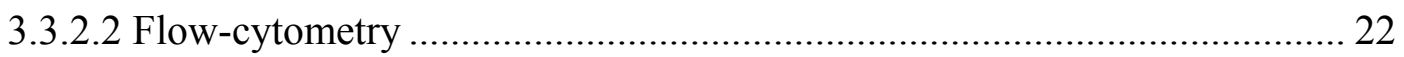

3.3.2.3 Sample preparation for flow-cytometry ………...................................... 22

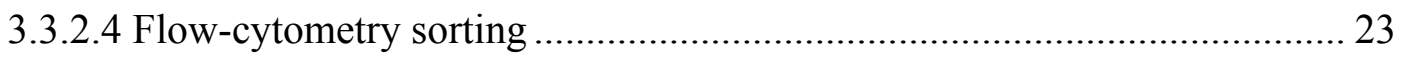

3.4 Bacterial Identification and Characterization of Microbial Community Structure. 23

3.4.1 Identification of Isolated Pure Bacterial Strains by Genomic Fingerprinting .. 23

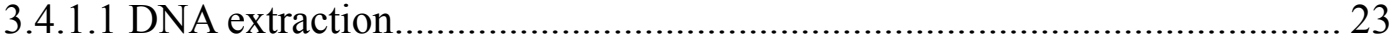

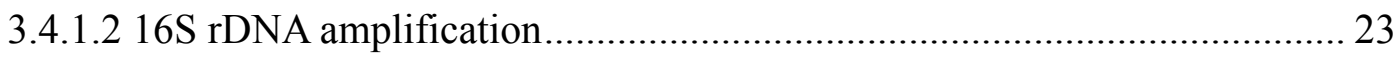

3.4.1.3 DNA sequencing and related analysis ....................................................... 24

3.4.2 Characterization of complex microbial community structure ……………...... 24

3.4.2.1 Construction and screening of a gene library ........................................... 24

3.4.2.2 Terminal-Restriction Fragment Length Polymorphism (T-RFLP) Analysis

3.5 High Performance Liquid Chromatography (HPLC) Analysis ................................. 26

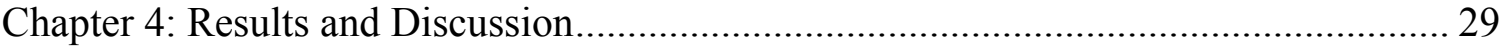

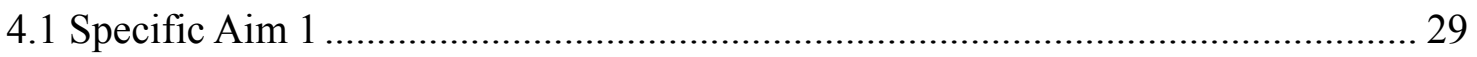

4.1.1 Effect of Triclosan on bacterial growth of activated sludge bacteria................. 29

4.1.2 Effect of the acclimation on Triclosan on the susceptibility of activated sludge

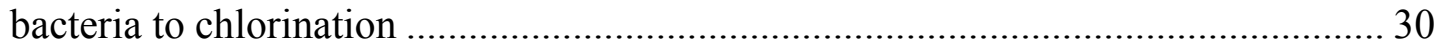

4.1.3 Effect of Triclosan on bacterial susceptibility to UV .......................................... 34

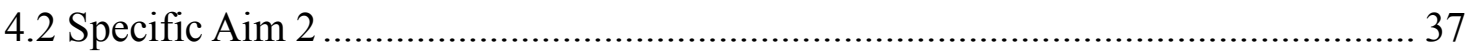

4.2.1 Investigation of the effect of Triclosan on bacteria community structure using

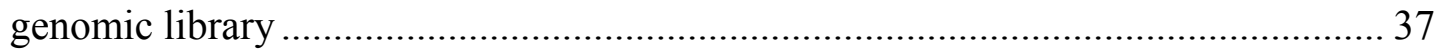

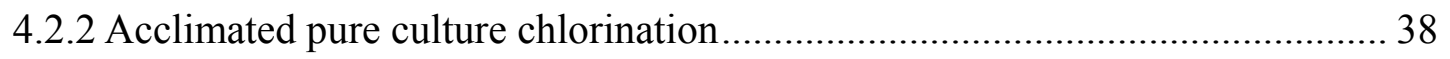

4.2.3 High Performance Liquid Chromatography (HPLC) analyses ......................... 40

4.2.3.1 Detection of Triclosan in activated sludge bacteria mixture acclimated to

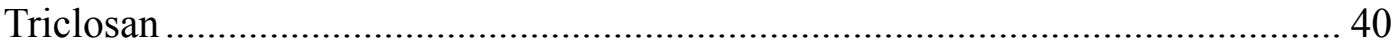

4.2.3.2 Detection of Triclosan in Triclosan-resistant pure cultures........................ 42

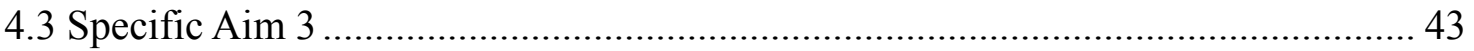

4.3.1 Microbial Community: Terminal-restriction fragment length polymorphism

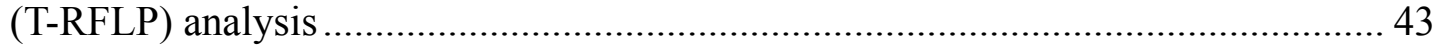

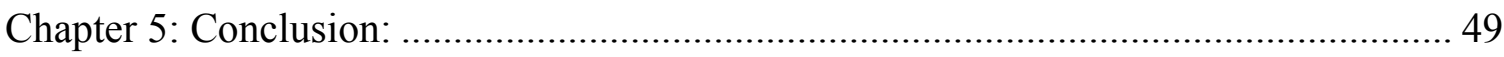

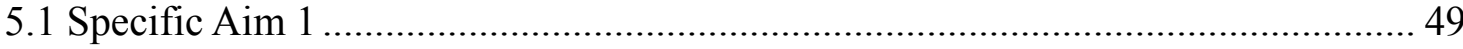

5.2 Specific Aim 2

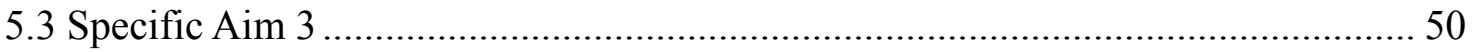




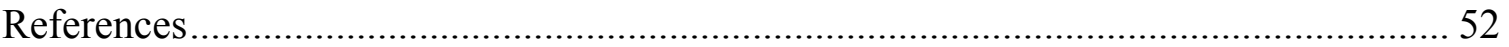




\section{List of Figures}

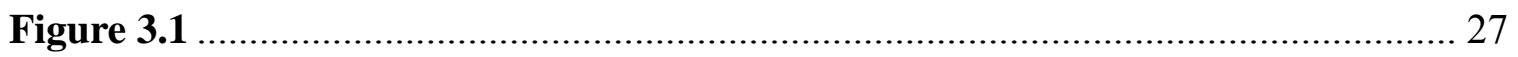

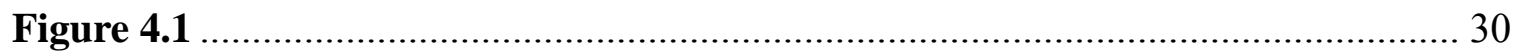

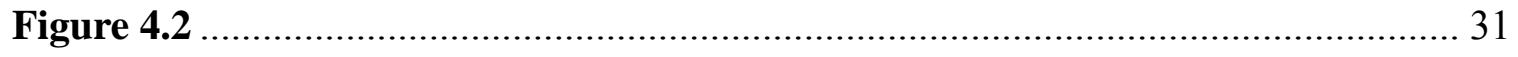

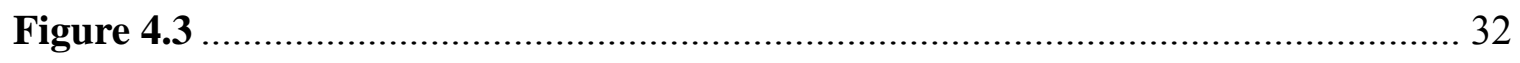

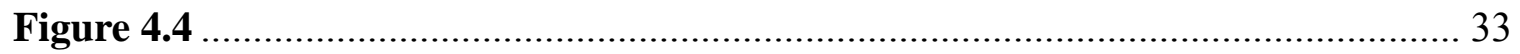

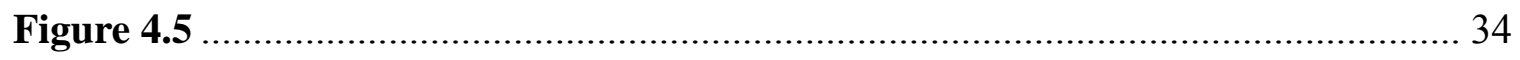

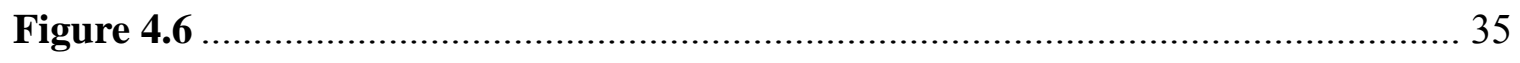

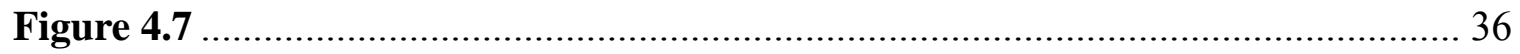

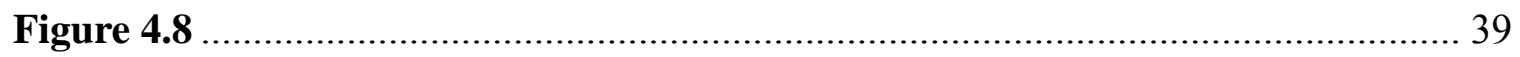

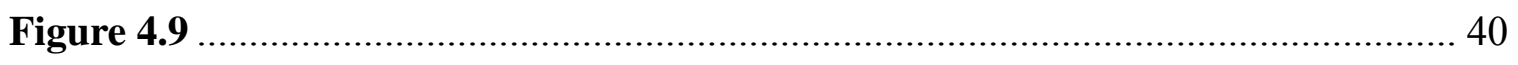

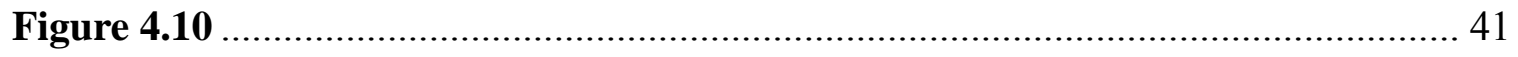

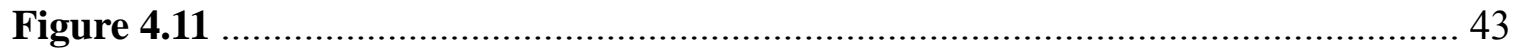

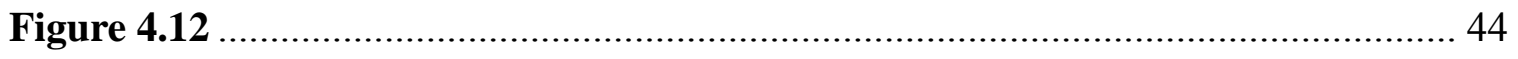

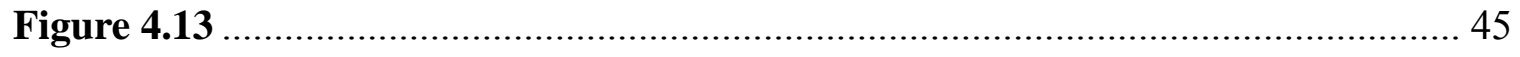

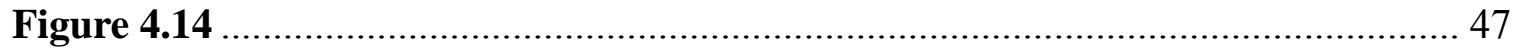

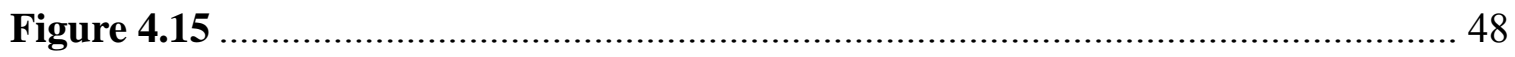

\section{List of Tables}

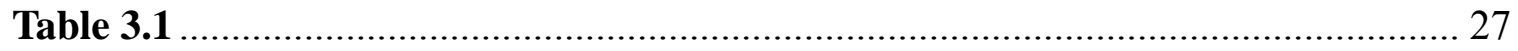

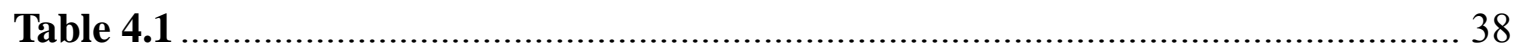


Chapter 1: Introduction

\section{Chapter 1: Introduction}

\subsection{Emergent Contaminants and Pharmaceutical and Personal Care Products (PPCPs)}

New environmental concerns have recently arisen from the increasing amounts of diverse chemicals produced, used, and disposed by all kind of industrial and agricultural activities, animal and human health care, and common household products (Koplin, 2002). Because these new or "emergent" contaminants are not well characterized regarding their environmental fate, including biodegradation, ecological impact, and biological activity, they represent a potential new threat for humans and the environment.

Of particular concern are the wide varieties of pharmaceuticals, household chemicals, and personal care products that are released into wastewater and directed through wastewater treatment processes. One particular aspect of "pharmaceuticals and personal care products" over other common industrial or agricultural pollutants is that they intent to stimulate a physiological response in humans and are biologically active at extremely low concentrations. Molecules of pharmaceuticals and personal care products are often designed to be resistant to biological degradation and metabolism in order to exert biological effect during a significant period of time and they are typically excreted largely unchanged.

Though little is known about the environmental fate of emergent contaminants, increasing evidence has shown their almost ubiquitous presence in streams and surface water. Pharmaceuticals and personal care products, as well as their degradation products and metabolites have been detected in virtually all compartments of the aquatic ecosystem (Koplin, 2002).

\subsection{Wastewater treatment plants as potential reservoirs of antimicrobial resistance}

Wastewater treatment plants that concentrate human wastes, antimicrobial agents, and resistant bacteria in a complex mixture of microorganisms (activated sludge) have been suggested to constitute ideal incubators for the development of new, multi-drug resistance (Levy and Marshall, 2004). Many reports have been published about the detection of 
resistant bacteria and resistance genes in wastewater treatment plants (Auerbach et al., 2007).

To prevent the dispersion of pathogens into the environment, wastewater treatments routinely include a disinfection phase that is applied as the last step of the treatment process. Commonly-used disinfectants in wastewater treatment include chlorine, ultraviolet irradiation (UV), and ozone $\left(\mathrm{O}_{3}\right)$. These disinfectants "inactivate" microorganisms prior to the effluents being discharged into receiving water.

\subsection{The antimicrobial agent Triclosan}

2-(2, 5-Dichlorophenoxy)-5-chlorophenol or Triclosan shows a broad spectrum and has been used as an antiseptic in personal care products, such as soap, toothpaste and antimicrobial additive in plastic and fabric materials, kitchen utensils, children's toys, and footwear (Schweizer et al., 2001). As a widely used antimicrobial agent, the environmental occurrence of Triclosan was reported and Triclosan has been largely detected in water, soil, sediment, and aquatic organisms. Although Triclosan is almost innocuous to higher organisms, it is suspected to have potential deleterious effects to the environment by its toxicity to bacteria and aquatic organisms, such as fish and algae (Orvos et al., 2002; McBain et al., 2003). Although Triclosan can be biodegraded by activated sludge bacteria and sorbed by sludge solid, the molecule is rather recalcitrant to bacterial metabolism and significant concentrations of Triclosan (up to 6\% of the concentration of waste water influent) are commonly detected in receiving water (Singer et al., 2002).

It is now an established fact that Triclosan, unlike most biocides, has activity against a specific target, the enoyl-acyl carrier protein reductase (ENR), an enzyme involved in the biosynthesis of fatty acids. Mechanisms of Triclosan resistance are similar the mechanisms involved in the resistance to important human antibiotics, raising concerns that exposure to Triclosan would induce cross-resistance to antibiotics (Singer, 2002). Municipal wastewater contains variable concentrations of Triclosan (from 0.07-14,000 $\mu \mathrm{g}$

$\mathrm{L}^{-1}$ ), therefore susceptible to induce antimicrobial resistance. Triclosan resistance may 
contribute to reduce bacterial susceptibility to clinically important antimicrobial agents, effective of the same target as Triclosan (i.e., ENR), due to either cross-resistance or co-resistance mechanism (Yazdankhah et al., 2006).

\subsection{Relationship between Antimicrobial Agents and Disinfection}

Antimicrobial resistance develops and persists in the environment as a result of selection pressure in the presence of antimicrobial agents, which, as shown in Kolpin et al. (2002), are known to be present in most streams and rivers across the U.S. Certain resistance mechanisms, developed in response to a specific drug, can also confer resistance to other antimicrobial agents, therefore inducing the possibility of "cross-resistance" between antibiotics and biocides (Russell 2003).

If antimicrobial agents and biocides are essential for the control of pathogens in the health care sphere, personal hygiene application, and the control of foodborne pathogens, increasing evidence suggests that exposure to biocides could reduce bacterial susceptibility to antimicrobial agents and disinfectants.

Though this constitutes today a controversial issue, there are increasing evidence that sub-lethal exposure to different antimicrobial agents could induce resistance to disinfection systems and vice-and-versa. For instance, Shrivastava et al. (2004) observed that the pathogen Pseudomonas aeruginosa resistant to chlorination in drinking water was resistant to several antibiotics tested. More intriguingly, it has been suggested that quaternary ammonium compounds (QACs) can induce cross-resistance and the selection of a disinfectant-resistant pathogens (Sidhu et al., 2002).

\subsection{Objective of the Research}

The published evidence that we collected and summarized above leads us to formulate the hypothesis that prolonged exposure of activated sludge bacteria to sub-lethal concentrations of Triclosan could possibly induce increasing resistance to commonly-used disinfectants, therefore raising the risk that dangerous pathogens being discharged into receiving water and the environment. Moreover, because exposure to 
Chapter 1: Introduction

Triclosan is suspected to induce resistance to important human antibiotics, bacteria escaping wastewater disinfection would represent an additional threat to human health.

The overall objective of this research was to investigate the effect of Triclosan on the susceptibility of activated sludge bacteria to common wastewater disinfection processes, such as UV and chlorination. The central hypothesis underlying this research is that Triclosan, by its antimicrobial properties, could modify the susceptibility to disinfection of activated sludge bacteria, therefore increasing the potential risk that pathogens are discharged into environment.

\subsection{Experimental Approach}

The overall experimental approach followed in this research can be summarized as follows. First, a complex bacterial community collected from an active sludge was acclimated over several sub-cultures in the presence of different concentrations of Triclosan (from 0.0 to $20 \mathrm{mg} \mathrm{L}^{-1}$ ) and then exposed to sub-lethal doses of chlorine and UV irradiation. Susceptibility of Triclosan-exposed bacterial suspensions to chlorination and UV irradiation was determined by direct colony forming unit (CFU) counting and by flow-cytometry (Specific Aim 1).

We then tried to determine the origin of the observed change of susceptibility by characterizing the microbial community structure by construction of gene library and restriction fragment length polymorphism (RFLP) analysis. We also investigated whether exposure to Triclosan could select bacterial species with a lower susceptibility to chlorination by the isolation a specific highly resistant strains from Triclosan-acclimated cultures (Specific Aim 2).

Finally, in order to investigate further the relative susceptibility to chlorination of different species in Triclosan-exposed activated sludge bacterial mixture, the microbial community structure was characterized by terminal-restriction fragment length polymorphism (T-RFLP) after sorting dead and living bacteria by flow-cytometry. 


\section{Chapter 2: Background and Literature Review}

\subsection{Environmental Concerns of Emergent Contaminants and PPCPs}

Recently, new concerns have arisen from the increasing amounts of extremely diverse, complex, and often poorly characterized chemicals produced, used, and disposed by all kind of industrial and agricultural activities, animal and human health care, and common household products (Koplin, 2002). It is estimated that approximately 70,000 xenobiotic compounds are currently in use in developed countries, and more than 1,000 new products are put on the market each year. Because these new or "emergent" contaminants are not well characterized, regarding their environmental fate, including persistence, biodegradation, global cycling, ecological impact, biological activity, and toxicity, they represent a new threat for humans and the environment. Our particular concern are the wide and spreading variety of pharmaceuticals, household chemicals, and personal care products that exhibit biological activity at high dose and are by nature design to resist fast biodegradation. Such compounds include human and veterinary antibiotics, biogenic hormones or hormone-mimics, and other drugs, and antimicrobial products that are released as a direct result of their human and animal consumption or their industrial or domestic use. These compounds are typically released into wastewater and are directed through wastewater treatment processes (including wastewater treatment plants and domestic septic processes). However, current wastewater processes are designed to remove high concentrations of suspended solids, biological oxygen demand, nutrients, and pathogens susceptible to impair the quality of receiving waters, but they are not specifically designed to treat small concentrations of highly diverse organic chemicals. Other emergent contaminants, by the nature of their application, escape wastewater treatment: Veterinary antibiotics and pharmaceuticals used for animal feeding and treatment, agricultural pesticides, and industrial antimicrobial agents and biocides are released into the environment though animal wastes, runoff, and leakage from structures or land application. One particular aspect of "pharmaceuticals and personal care products" over other common industrial or agricultural pollutants is that they intent to stimulate a physiological response in humans and other forms of life and are biologically active at extremely low concentrations. 
Though little is known about the source, environmental fate, persistence, occurrence, and biological activity of emergent contaminants, increasing evidence has shown their almost ubiquitous presence in streams and surface water (National Research Council, 1999). Pharmaceuticals and personal care products, as well as their degradation products and metabolites have been detected in virtually all compartments of the aquatic ecosystem, including surface waters (rivers, streams, lakes, estuaries, and sea waters), wastewater, groundwater, drinking water, and effluents from wastewater treatment. Pharmaceuticals are defined as "compounds responsible for physiological or pharmacological action and used in the diagnosis, cure mitigation, treatment, or prevention of disease in humans" (Anderson, 2003).

Pharmaceuticals and personal care products typically enter the environment by excretion following therapeutic use or disposal of unused products that are released into wastewater and not efficiently removed by wastewater treatment facilities, and are eventually discharged into receiving waters (Rule 2005).

\subsection{Biological Effects of Exposure to Antimicrobial Agent}

Ecological of human health and personal care chemicals released in the environment are still not well characterized, even though they are suspected to have a significant biological effect on wildlife. Widespread antimicrobial agents commonly used in soaps, detergents, and toothpastes (such as Triclosan) intend to inactivate potential pathogens, but they may also exert unsuspected and unintended biological activity on specific non-target organisms simultaneously present in the ecosystem. Moreover, such drugs and chemicals may act in synergy and/or as antagonists of other chemicals present in the environment (Wilson 2003).

\subsubsection{Antimicrobial resistance mechanisms}

Antimicrobial resistance develops and persists in the environment as a result of selection pressure in the presence of antimicrobial agents, which, as shown in Kolpin et al. (2002), are known to be present in most streams and rivers across the U.S. Multiple resistance 
genes or multi-target resistance genes confer resistance to a range of antimicrobial agents, making infection very difficult to treat. Known examples involve methicillin-resistant Staphyloccocus aureus (MRSA) and vancomycin-resistant Enterococci (VRE) (Levy and Marshall, 2004). Certain resistance mechanisms, developed in response to a specific drug, can also confer resistance to other antimicrobial agents, therefore inducing the possibility of "cross-resistance" between antibiotics and biocides (Russell 2002). Horizontal gene transfer plays a central role in the dispersion of antimicrobial resistance among and across bacterial species. Antimicrobial resistance mechanisms are commonly encoded by genes that are located on genetic mobile elements such as fragments of genomic DNA, plasmids, and transposons (Davison 1999; Hastings et al., 2004; Pruden et al., 2006).

Although antimicrobial resistance mechanisms are widely diverse, they can be summarized as follows: Reduction of antibiotic uptake (impermeability or efflux), drug biodegradation (enzymatic attack), modification of specific the antibiotic target site, overproduction of the target, and bypass of the target, absence of intracellular metabolic activation of the antibiotic (isoniazid) (Levy 1997).

\subsubsection{Wastewater treatment plants as potential reservoirs of antimicrobial resistance}

Wastewater treatment plants that concentrate human wastes, antimicrobial agents, and resistant bacteria in a complex mixture of microorganisms (activated sludge) have been suggested to constitute ideal incubators for the development of new, multi-drug resistance (Reinthaler et al., 2003; Levy and Marshall, 2004; Kummerer 2004). For instance, studying vanA genes of enterococci (vancomycin resistance) and mecA genes of staphylococci (methicillin resistance) in different wastewaters and biofilms, Schwartz et al. (2003) showed that wastewater treatments reduced the levels of antimicrobial resistance genes in treated effluents, but still resulted in substantial discharge of biologically-active genetic material into receiving water.

To prevent the dispersion of pathogens into the environment, wastewater treatments routinely include a disinfection phase that is applied as the last step of the treatment process. Commonly-used disinfectants in wastewater treatment include chlorine, 
ultraviolet irradiation (UV), and ozone $\left(\mathrm{O}_{3}\right)$ (Haas and Englebrect, 1980; Paraskeva and Graham, 2002; Hijnen et al., 2006). These disinfectants kill or "inactivate" microorganisms (inability to reproduce) prior to the effluents being discharged into receiving water.

\subsection{Relationship between Antimicrobial Agents and Disinfection}

Though this constitutes today a controversial issue, there are increasing evidence that sub-lethal exposure to different antimicrobial agents could induce resistance to disinfection systems and vice-and-versa. For instance, Shrivastava et al. (2003) observed that the pathogen Pseudomonas aeruginosa resistant to chlorination in drinking water was resistant to several antibiotics tested, including Nalidixic acid, Gentamicin, Cefotaxime and Amikacin. Although the authors were unable to isolate potential responsible for chlorine resistance, further laboratory experiments showed that only antibiotic-resistant strains were able to survive high chlorine treatment. There are many reports about the development of bacterial resistance to disinfection systems used for the treatment of water (Ridgway and Olson 1982; D'Auria et al., 1989; Pyle et al., 1994; Le Dantec et al., 2002). Generally speaking, most sensitive bacteria, including Pseudomonas spp., are inactivated by chlorine concentrations of $1.0 \mathrm{mg} \mathrm{L}^{-1}$. For instance, P. cepacia strains with reduced susceptibility to iodine and to chlorination and biofilms of $P$. aeruginosa and Klebsiella pneumoniae resistant to hypochlorite and chlorosulfamates have been isolated (Stewart et al., 2001). More intriguingly, it has been suggested that quaternary ammonium compounds (QACs), such as benzalkonium chloride, cetylpyridinium chloride, and detizor, frequently used in hospitals can induce cross-resistance and the selection of a disinfectant-resistant pathogens (Sidhu et al., 2002).

\subsection{The Antimicrobial Agent Triclosan}

\subsubsection{Generality of Triclosan}

2-(2, 5-Dichlorophenoxy)-5-chlorophenol or Triclosan (Figure 1) shows a broad spectrum germicidal activity and low toxicity to human (Moretro, 2006). Because of its antifungal and antiviral properties, high thermal stability, during the last 30 years, Triclosan has 
been a widely used for a wide variety of commercial and household applications.

Triclosan has been used as an antiseptic in personal care products, such as soap, toothpaste (concentrations range from 0.1 to $1 \%$ ), and antimicrobial additive in plastic and fabric materials, kitchen utensils, children's toys, and footwear (Rule 2005; Schweizer et al., 2001). In Europe, over 350 tons of Triclosan are used every year as an antimicrobial agent in a variety of products (Irgasan, 1998). As a widely used antimicrobial agent, the environmental occurrence of Triclosan was reported and Triclosan has been largely detected in water, soil, sediment, and aquatic organisms. As many pharmaceuticals and personal care products, Triclosan is not efficiently removed by wastewater treatment. This and the land-application of Triclosan-contaminated biosolids, and infiltration from sewer pipes have lead to contamination of soil, groundwater, and surface water (Rule 2005). Though Triclosan is almost innocuous to higher organisms as humans, it is suspected to have potential deleterious effects to the environment by its toxicity to bacteria and aquatic organisms, such as fish and algae (Orvos et al., 2002; McBain et al., 2003).

Beside its intrinsic toxicity, transformation of Triclosan into chlorodioxins by incineration or the action of sunlight constitutes a further concern. Another mechanism of Triclosan transformation includes biological or abiotic methylation by higher organisms as fishes. Although biomethylation of Triclosan has been reported, it is still unclear whether Triclosan itself can be accumulated with the methylation happening after uptake by the fishes (Lindstrom 2005; Swofford 2005)

\subsubsection{Biological activity of Triclosan}

It is now an established fact that Triclosan, in a sub-lethal concentration, has activity against a specific target. Exposure experiments conducted first using E. coli, Mycobacterium smegmatic, and M. tuberculosis, established that Triclosan interact with enoyl-acyl carrier protein reductase (ENR), an enzyme involved in the biosynthesis of fatty acids necessary for the cell wall synthesis. Triclosan-specific activity therefore make highly likely that the compound could induce antimicrobial resistance against other antimicrobial agents targeting the same biological pathway. However, when used at high 
doses usually employed in many of its applications, it is suspected that Triclosan would lead to cell lyses by several mechanisms. However, currently clearly identified mechanisms of Triclosan resistance are similar the mechanisms involved in the resistance to important human antibiotics, raising concerns that exposure to Triclosan would induce cross-resistance to antibiotics (Singer, 2002).

\subsubsection{Environmental concerns of Triclosan spread}

\subsubsection{Toxicity of Triclosan}

Triclosan has been found in many different environments and even in human milk, although nothing is known about the potential effect of Triclosan on the development of exposed children. Triclosan exerts acute toxic to aquatic organisms such as algae (Scenedesmus subspicatus) and fishes (EC50 for rainbow trout $=350 \mu \mathrm{g} \mathrm{L}^{-1}$ ) (Singer, 2002; Lindstrom, 2005). There are concerns that Triclosan may affect the structure and functions of algal communities in contaminated aquatic ecosystems, with effects on the natural nutrient removal and cycling, potentially affecting the entire ecological balance of natural waters (Wilson 2003). It is generally accepted that Triclosan in natural waters is susceptible to biodegradation, photolysis, and adsorption to solid surfaces. Removal rates of Triclosan from stream water ranges from 0.21 to $0.33 \mathrm{~h}^{-1}$ (Mag Brook, England) and $0.06 \mathrm{~h}^{-1}$ (Cibolo Creek, Texas) (Rule 2005). On the other hand, as a lipophilic compound, Triclosan has the tendency to adsorb to solid particles and has been detected in marine sediments contaminated by wastewater treatment effluents at concentrations ranging from 0.27 to $131 \mu \mathrm{g} \mathrm{kg}{ }^{-1}$ (Aguera et al., 2003).

\subsubsection{Biodegradation resistance and by-products of Triclosan}

A few bacterial species have been described as capable of mineralizing the aromatic ring of Triclosan partially, using it as both energy and sole carbon source, such as Pseudomonas putida TriRY and Alcaligenes xylosoxidans subsp. denitrificans TR1 (Hay,et al, 2001; Meade, 2001). Although Triclosan can be biodegraded by activated sludge bacteria and adsorbed by sludge solid, the molecule is rather recalcitrant to bacterial metabolism and significant concentrations of Triclosan (up to 6\% of the concentration of waste water influent) are commonly detected in receiving water (Singer 
et al., 2002). Indeed, under certain conditions, such as in the presence of hypochlorite, sunlight, and heat, Triclosan has also been shown to be transformed to be more toxic and stable derivatives, such as chlorophenols, polychlorinated biphenyl ethers, and dioxins (Mezcua et al., 2004).

\subsubsection{Typical concentrations in WWTPS}

In wastewater, Triclosan concentration of influent could be as high as $14 \mathrm{mg} \mathrm{L}^{-1}$ and $6 \%$ residual in receiving water (no effect concentration (NEC) is $50 \mathrm{ng} \mathrm{L}^{-1}$ ) (Singer et al., 2002; Halden and Paull, 2005).

Removal of Triclosan in wastewater treatment plants is highly variable and depends on the type of secondary and tertiary treatment applied: Removal percentages vary between 0 and $100 \%$. Activated sludge processes are characterized by $90 \%$-percentages removal (Singer, 2002). Drinking water supply has also been found to contain Triclosan. As lipophilic compounds, Triclosan tends to be adsorbed to organic material and bio-solids from water treatment may contain up to $30 \%$ of the influent concentration (Rule 2005).

In a comprehensive study on 139 U.S. streams, it is reported that Triclosan was found in $58 \%$ of the streams at a median concentration of $0.14 \mu \mathrm{g} \mathrm{L}^{-1}$ and a maximum concentration of $2.3 \mu \mathrm{g} \mathrm{L}^{-1}$ (Rule et al., 2005).

\subsubsection{Physiological effects of Triclosan}

Triclosan is known to have an activity against a wide range of Gram-positive and Gram-negative bacteria. Triclosan is classified as bacteriostatic at low concentrations and bactericidal higher concentrations (Russell, 2004).Generally, at high bactericidal concentrations, Triclosan appears to act nonspecifically upon multitude targets, causing disruption of bacterial cell wall functions (Yazdankhah et al., 2006). At low sub-lethal concentrations, Triclosan is suspected to affect more specific targets. Currently, Triclosan is known to inhibit one specific protein, the bacterial enoyl-acyl carrier protein reductase (ENR), an enzyme involved in fatty acid biosynthesis and cell wall building (Ling et al., 2004). Triclosan is suggested to inhibit fatty acid synthesis by interfering with the NADP 
Chapter 2: Background and Literature Review

binding site of the enoyl-ACP reductase (Hay 2001).

\subsubsection{Relationship between Triclosan and development of antimicrobial resistance}

Specific resistance to Triclosan includes mutation of the target, increasing target expression, efflux-pump, and enzymatic inactivation and biodegradation (Schweizer et al., 2001). Even though Triclosan resistance does not frequently appear as specific gene mutation or efflux pumps over-expression (Bayston et al., 2007), some specific Triclosan-tolerant bacteria may develop resistance if they are selected in the presence of sub-lethal concentrations of Triclosan long enough to induce physiological changes and/or gene mutations (Sanchez et al., 2005). Municipal wastewater contains variety concentrations of Triclosan (from $0.07-14,000 \mu \mathrm{g} \mathrm{L}^{-1}$ ), therefore susceptible to induce antimicrobial resistance. Triclosan resistance may contribute to reduce bacterial susceptibility to clinically important antimicrobial agents, effective of the same target as Triclosan (i.e., ENR), due to either cross-resistance or co-resistance mechanism (Yazdankhah et al., 2006).

Several bacterial species have been identified that are highly resistant to Triclosan, including Triclosan-tolerant strains in the groups of pseudomonads and stenotrophomonads, and Serratia marcescens and Pseudomonas fluorescens, isolated from a food processing facility previously (McBain et al. 2003 and Moretro et al., 2006). S. marcescens is at the origin of a common hospital-acquired infection, which is difficult to treat because of its high resistance to a broad range of antibiotic, including imipenem, aminoglycosides, and aztreonam (Kumar and Worobec, 2005). Efflux pump acts has been identified as the major multi-drug resistance mechanism of S. marcescens (Kumar and Worobec, 2002).

\subsection{Wastewater Treatment}

Usually wastewater treatment plants include a disinfection step designed to inactivate pathogens before discharging treated water into the environment. Disinfection is the last process of water treatment, proceeding with chemical or physical methods, such as UV, chlorination, ozone and $\mathrm{TiO}_{2}$. With the presence of emerging contaminants, such as 
pharmaceuticals and personal care products (PPCPs) and antimicrobial agents into sewage, disinfection efficiency is facing a new challenge in water treatment progress. Hence, a new risk to public health is generated.

The activated sludge process in wastewater treatment plants collects daily wastes, antimicrobials, and bacteria in a complex environment, which consists a potentially "ideal incubator" for the emergence of new, multi-drug resistance (Reinthaler et al., 2003; Levi and Marshall, 2004; Kummerer, 2004). It is well known that antimicrobial resistance can spread by living resistant bacteria, and by horizontal gene transfer involving mobile genetic elements (plasmids), bacteriophages, or fragments of genomic DNA (Guardabassi et al., 2002; Hastings et al., 2004; Pruden et al., 2006).

Typically, in waste water treatment plant, disinfection is the last step of waste water process to kill microorganisms, especially the pathogens which are hazardous to human health. Disinfection could be performance as both chemical and physical methods, such as chlorination, $\mathrm{O}_{3}$ (chemical method), and UV-light (physic method), or combinated by several methods, e.g., $\mathrm{O}_{3}-\mathrm{UV}$ system. Chlorination and UV disinfection are the two widely spread methods used by most of the waste water treatment plants (Hijnen et al., 2006).

\subsubsection{Chlorination}

The mechanisms of disinfection processes are not fully understood. Chlorine (as well as advanced oxidation systems, such as $\mathrm{O}_{3}, \mathrm{O}_{3}-\mathrm{UV}$, or $\mathrm{O}_{3}-\mathrm{H}_{2} \mathrm{O}_{2}$ ) is believed to act as strong oxidants, reacting in a non-specific manner with all biological molecules, either directly or by the generation of free radical species and/or reactive oxygen species (ROS). Effects include the disruption of cell permeability, damage to enzymes, and to nucleic acids (Cho et al., 2003). Cyto-toxicity of chlorine, $\mathrm{Cl}_{2}$, is due mainly to its hydrolysis product, hypochlorous acid ( $\mathrm{HOCl})$. $\mathrm{HOCl}$ has long been used as an antiseptic agent and is still currently the major disinfectant used in public water supplies and wastewater treatment facilities. The physiological effect of $\mathrm{HOCl}$ is attributed to reactivity with a range of biological molecules, including amines, $S$-containing compounds, proteins, fatty acids, 
nucleotides, DNA, and RNA (Prütz, 1996). Reported inactivation doses of free chlorine depend on the cell type and range from.

\subsubsection{UV irradiation}

UV light is believed to affect primarily nucleic acids, leading to the formation of pyrimidine dimers and pyrimidone photoproducts (Hijnen et al., 2006). The damage of short wave UV (UVC) to DNA is mostly known for the formation of dimers such as cyclobutane pyrimidine dimers and pyrimidine-pyrimidone photoproducts via photochemical reactions (Häder and Sinha, 2005; Harm, 1980). Because it induces DNA damage, UV disinfection may be more efficient for the destruction of resistance genes. Although the germicidal properties of UV irradiation are known since the early 1900's, its general application in water treatment has long been hampered by high costs, poor equipment reliability, and the advent of chlorination. Recently, UV disinfection regains more attention due to the discovery of toxic chlorine by-products and the high efficacy of UV against Cryptosporidium and Giardia.

\subsection{Objective of the Research}

The published evidence that we collected and summarized above lead us to formulate the hypothesis that prolonged exposure of activated sludge bacteria to sub-lethal concentrations of Triclosan could possibly induce increasing resistance to commonly-used disinfectants, therefore raising the risk that dangerous pathogens being discharged into receiving water and the environment. Moreover, because exposure to Triclosan is suspected to induce resistance to important human antibiotics, bacteria escaping wastewater disinfection would represent an additional threat to human health.

The overall objective of this research is to investigate the effect of Triclosan on the susceptibility of activated sludge bacteria to common wastewater disinfection processes, such as UV and chlorination.

Except a few publications presented above, there is very little information available about the potential cross-resistance between antimicrobial agents, such as Triclosan, and 
Chapter 2: Background and Literature Review

disinfection systems. Our research is significant because it is expected to pave the way for more research about the long term effect of antimicrobial drugs on bacterial resistance to disinfection and the potential need for improved and alternate disinfection systems in wastewater.

\subsection{Research Hypothesis}

The central hypothesis underlying this research is that Triclosan, by its antimicrobial properties, could modify the susceptibility to disinfection of activated sludge bacteria, therefore increasing the potential risk that pathogens are discharged into environment.

In order to test our central hypothesis, the following specific aims were pursuit:

Specific Aim 1: The goal of this specific aim was to test the hypothesis that exposure to Triclosan modifies the susceptibility of activated sludge bacteria to chlorination and UV.

Specific Aim 2: The objective as this specific Aim was to determine the origin of the change in susceptibility observed in Specific Aim 1. This specific aim involved two sub-tasks:

First, we wanted to test if the observed change in susceptibility to chlorination can be explained by a shift in the microbial community structure.

Second, we tried to determine if the observed change in susceptibility can be explained by an induced tolerance of Triclosan-resistant strains.

Specific Aim 3: Finally, in the last specific aim, we attempted to further investigate the relative susceptibility of different activated sludge bacteria acclimated in the presence and in the absence of Triclosan. 


\subsection{Overview of Terminal-restriction fragment length polymorphism and}

\section{Flow-cytometry}

\subsubsection{Terminal-restriction fragment length polymorphism (T-RFLP) analysis}

Terminal restriction fragment length polymorphism (T-RFLP) analysis is typically used to analyze microbial community diversity through PCR-fingerprinting. T-RFLP analysis is a combination of several technologies, including PCR, nucleic acid electrophoresis, and comparative genomics. PCR is first used to amplify a specific genetic marker; the resulting population of genes (from different organisms) is then digested using specific restriction enzymes, resulting in a second sub-population of DNA fragments of different size. Fragments are separated by electrophoresis and analyzed using functional genomic, allowing to compare different communities, including bacteria, archaea, fungi, even other phylogenetic groups, as well as functional genes. T-RLFP analysis is rapid and highly reproducible. Based on these properties, this method could detect more diverse units in a community than other PCR fingerprinting related methods. In T-RFLP analysis, the detection of restriction fragments is extremely accurate, because the fluorophores of the restriction fragment are compared by standard size markers (Marsh, 1999).

For the inherent method problem, the data analysis system for T-RFLP, which focuses on the link between the size of terminal restriction fragments and sequence databases, is not sufficient to relate to the taxonomic position. However, T-RFLP system is a convenient molecular approach, because this method can collect significant information for the investigation of microbial community structure and member density distribution (Thies 2007).

\subsubsection{Flow-cytometry analysis and cell sorting}

Flow-cytometry system can be used for analyzing cell numbers, cell size distribution and individual cell characteristics based on biochemistry and physiology. The method can rapidly analyze numerous cells individually in suspension, and reveal heterogeneity that communities presented. Three unique technical properties of low-cytometry system offer a high potential for the investigation of the microbiological characteristics in aquatic 
systems: (i) The high number of cells that can be individually analyzed in a short time; (ii) the sorting capacity of some cytometers, which allows the separation of specific populations, thus allowing further physical, biological or molecular characterization; and (iii) the multiparametric data acquisition and multivariate data analysis.

The use of specific cell permanent fluorescent dyes (e.g., Syto61) that cross easily bacterial membranes and bind to nucleic acids, and exclusion fluorescent dyes, such as propidium iodide (PI), that are prevented to enter the cell with intact membranes allows to characterize the populations of living and dead bacterial cells.

Basically, single particles (cells) pass through the flow cell and in front of a focus point where fluorescent particles are excited by a light beam of defined wavelength. The specific signals emitted by specific fluorescent dyes bound to the cells are then recorded. 
Chapter 3: Materials and Methods

\section{Chapter 3: Materials and Methods}

\subsection{Quality Assurance and Control (QC/QA)}

QC/QA will be ensured by the use of recognized protocols described in Manual of Environmental Microbiology (Hurst, 2002), Methods for General and Molecular Bacteriology (Gerhardt et al., 1994), and Standard Protocols in Molecular Biology (Ausubel et al., 1999; Sambrook and Russel, 2001).

\subsection{Activated Sludge Treatment}

\subsubsection{Sample preparation}

Samples of wastewater were collected in a nearby wastewater treatment plant (Morgantown Utility Board, Star City, WV). This wastewater treatment plant treats most of the domestic wastewater of the City of Morgantown (WV), representing about 14,000 customers. The facility is representative of many medium size wastewater treatment facilities in the U.S. Samples were stored at $4{ }^{\circ} \mathrm{C}$ and processed in the lab within $48 \mathrm{~h}$. All subsequent steps were performed under sterile conditions.

\subsubsection{Bacteria medium}

Bacteria cells in pure cultures were grown routinely on Luria Bertani (LB) medium. LB medium consists in tryptone $10 \mathrm{~g}$, yeast extract $5 \mathrm{~g}$ and sodium chloride $10 \mathrm{~g}$ per liter. For solid medium, LB agar plates were prepared using LB Agar Miller, (Fisher Scientific, Fair Lawn, NJ) according to the manufacturer specifications. Pure bacteria in liquid medium were cultivated on LB broth medium was prepared by mixing $25 \mathrm{~g}$ LB broth (Fisher Scientific, Fair Lawn, NJ) with 1 L D.I. water, and autoclaved at $121^{\circ} \mathrm{C}$ for $15 \mathrm{~min}$.

Activated sludge bacterial mixtures were cultivated in sewage feed medium according to EPA Method OPPTS 850.6800 (EPA, 1996). Sewage feed medium was prepared by mixing peptone $10 \mathrm{~g}$, meat extract $11 \mathrm{~g}$, urea $3 \mathrm{~g}, \mathrm{NaCl} 0.7 \mathrm{~g}, \mathrm{CaCl}_{2} \cdot \mathrm{H}_{2} \mathrm{O} 0.4 \mathrm{~g}, \mathrm{MgSO}_{4} \cdot 7 \mathrm{H}_{2} \mathrm{O} 0.2 \mathrm{~g}$, $\mathrm{K}_{2} \mathrm{HPO}_{4} 2.8 \mathrm{~g}$, and dissolving in $\sim 850 \mathrm{~mL}$ D.I (deionized) water. The medium was adjusted to $\mathrm{pH}=6.5$ with $\mathrm{NaOH}$ and watered to $1 \mathrm{~L}$. The medium was filter-sterilized on $0.2 \mu \mathrm{m}$ and stored at $4{ }^{\circ} \mathrm{C}$ for no more than 2 months. 


\subsubsection{Preparation of activated sludge bacteria}

Bacterial mixtures were prepared from activated sludge mixture by homogenizing by 5 $10 \mathrm{sec}$ pulses for $5 \mathrm{~min}$ with a $500-\mathrm{W}$ blender to disaggregate bacterial flocks. Then the suspension was filtrated on Whatmann paper $(11-\mu \mathrm{m}$ pore size) to remove remaining flocks and bacterial aggregates. The optical density (O.D.) of the filtrated suspension was measured at $600 \mathrm{~nm}$ to evaluate the number of bacteria cells. Bacterial suspension was stored at $4{ }^{\circ} \mathrm{C}$ for no more than 24 hours and used for Triclosan exposure experiment and DNA extraction.

\subsubsection{Isolation of pure cultures from activated sludge mixture}

Prepared activated sludge bacterial suspension was diluted in sterile PBS to reach an O.D. $600=0.5$ (optical density quantification at $600 \mathrm{~nm}$ ), and spread on LB agar plates for bacterial isolation and identification. Pure cultures were prepared by picking single colonies from the LB agar plates and incubation in LB broth medium in $25^{\circ} \mathrm{C}$ at $150 \mathrm{rpm}$ overnight.

\subsubsection{Culture growth and exposure to Triclosan (mix cultures and pure cultures)} Triclosan (minimum 96\% purity (GC), Tokyo Chemical Industry, Tokyo, Japan) stock solutions were prepared by dissolving $100 \mathrm{mg}$ Triclosan into 10 or $100 \mathrm{~mL}$ dimethyl sulphoxide $\left(\left(\mathrm{CH}_{3}\right)_{2} \mathrm{SO}\right)$ to get $10 \mathrm{mg} \mathrm{L}^{-1}$ or $1.0 \mathrm{mg} \mathrm{L}^{-1}$ stock. $0.2 \%$ dimethyl sulphoxide does not have significant toxic action on activated sludge suspension and is not normally a metabolizable substrate for bacteria (Neumegen et al., 2005).

Bacteria suspensions prepared from activated sludge were cultivated in liquid medium (activated sludge mix cultures on Sewage feed medium and pure bacterial cultures on LB broth medium). Triclosan stock solution was added to obtain different final concentrations ranging from 0 to $20 \mathrm{mg} \mathrm{L}^{-1}$. Cultures were then incubated at $25^{\circ} \mathrm{C}, 150 \mathrm{rpm}$ for $24 \mathrm{~h}, 48 \mathrm{~h}$, or $72 \mathrm{~h}$. Sample aliquots were collected periodically and quantified by measuring optical density at specific time points using a spectrophotometer at $600 \mathrm{~nm}$.

Acclimation on Triclosan was achieved by conducting at least three successive subcultures 
in the presence of consistent concentration of Triclosan ranging from 0 to $20 \mathrm{mg} \mathrm{L}^{-1}$. Second sub-cultures were then prepared by inoculation of a small aliquot of $48-\mathrm{h}$ Triclosan-exposed bacterial suspension in the presence of the same concentration of Triclosan and incubation under similar conditions $\left(25^{\circ} \mathrm{C}, 150 \mathrm{rpm}\right)$. Third subcultures were similarly conducted using bacterial inoculums collected from the second subcultures. Further subcultures, when used, were prepared by repetition of the process.

\subsubsection{Preparation of resting cells}

Ten-mL aliquots of bacteria cells collected from Triclosan-acclimated sub-cultures were introduced into $15-\mathrm{mL}$ sterile centrifugation tubes and harvested by centrifugation for 10 min at 3,000 rpm under refrigeration. The resulting bacterial pellet was then washed two times with PBS by successive resuspended in sterile PBS and centrifugation. Resting cells were finally obtained after suspending the bacteria pellets of each sample with the same volume of PBS.

\subsection{Disinfection Experiments}

\subsubsection{Chlorination of Triclosan acclimated bacteria}

\subsubsection{Preparation of cell suspensions}

Triclosan-acclimated, PBS-washed resting cell suspensions from activated sludge

mixtures or pure cultures were diluted in sterile PBS to reach a final O.D. ${ }_{600}=0.05$ (optical density quantification at $600 \mathrm{~nm})$.

\subsubsection{Chlorine exposure}

Sodium hypochlorite ( $\mathrm{NaClO})$ (5\% available $\mathrm{Cl}_{2}$, RICCA Chemical Company, Arlington, Texas) stock solutions were prepared from a 5\% $\mathrm{NaClO}$ solution (commercial bleach). 10 $\mathrm{mL}$ of diluted bacterial suspensions (pure or mixed cultures) were exposed to increasing chlorine doses for 15 min under mixing by a magnetic stirrer. Chlorine was added as sodium hypochlorite $(\mathrm{NaClO})$ aqueous solution to a concentration calculated to achieve a dose ranging from 0.0 to $10.0 \mathrm{mg} \mathrm{Cl} \mathrm{L}^{-1} \mathrm{~min}$. The chlorine dose was defined as follows:

\section{Dose $\left(\mathrm{mg} \mathrm{Cl} \mathrm{L} \mathrm{L}^{-1} \mathrm{~min}\right)=$ Free chlorine concentration $\left(\mathrm{mg} \mathrm{L}^{-1}\right) \times$ Exposure time $(\mathrm{min})$}


After $15 \mathrm{~min}$, residual free chlorine $\left(\mathrm{ClO}^{-}+\mathrm{HClO}\right)$ was neutralized by the addition of an excess dose of sodium thiosulfate $\left(\mathrm{Na}_{2} \mathrm{~S}_{2} \mathrm{O}_{3}\right)$. Effect of chlorination on cell viability was determined by CFU counting and flow-cytometry analysis. Initial chlorine demand was determined by addition of a known excess of chlorine and measurement of residual chlorine (diethyl-p-phenylenediamine method) after stabilization.

\subsubsection{UV irradiation}

A UV collimated beam unit that employs a low-pressure UV mercury lamp (Atlantic Ultraviolet, Hauppauge, NY) that emits predominantly radiation at $254 \mathrm{~nm}$ (UV) will be used in the study. The range of UV dose applied in the disinfection will be from 0.0 to 200 $\mathrm{mJ} \mathrm{cm}{ }^{-2}$ to allow significant log-inactivation of the microorganisms. The dose range covers the typical averaged UV dose delivered by UV disinfection system in wastewater treatment plants. The UV dose will be determined based on the definition by Blatchley and Hunt (1994), that is, dose $=\mathrm{UV}$ intensity $\left(I, \mathrm{~mJ} \mathrm{~cm}^{-2}\right)$ times exposure time $(t, \mathrm{sec})$. The UV intensity will be measured with a detector SEL240 (International Light, Peabody, MS) and radiometer IL1400A (International Light) and exposure time will be adjusted to the desired dose.

Fifteen-mL aliquots of cell suspensions will be exposed for 5 min to increasing doses of UV in 20 -mL shallow quartz dishes under magnetic stirring. UV intensity at the surface of the liquid will be measured $\left(0.1-0.2 \mathrm{~mW} \mathrm{~cm}^{-2}\right)$ and samples will be exposed during increasing time, resulting in doses ranging from 0.0 to $200 \mathrm{~mJ} \mathrm{~cm}^{-2}$. Exposed bacterial cell will be tested for cell viability and used for DNA extraction.

\subsubsection{Determination of cell viability}

The effect of disinfection on cell viability was determined by plating serial dilutions on synthetic sewage feed agar (EPA, 1996) and colony forming units (CFU) counting, and flow-cytometry analysis. 


\subsubsection{Colony forming units (CFU) counting}

Bacterial cultures (pure cultures or mixed culture) were serial diluted in sterile phosphate buffer saline solution (PBS) (1x): $10 \mu \mathrm{L}$ of bacteria suspension were diluted into $10 \mathrm{~mL}$ PBS and mixed, then $10 \mu \mathrm{L}$ were collected from the previous diluted suspension and add into another $10 \mathrm{~mL}$ PBS and mixed, etc.). $100 \mu \mathrm{L}$ of the final suspension were then plated onto LB agar and incubated at $25^{\circ} \mathrm{C}$ for $24 \mathrm{~h}$. Colonies were visually counted for determination of cell viability.

\subsubsection{Flow-cytometry}

Flow-cytometry was used to measure the percentage of living and dead bacterial cells after exposure of Triclosan-acclimated cell suspensions to disinfection, chlorination and UV irradiation. Because only a slight percentage of environmental bacteria are cultivable, cell viability was also determined by flow-cytometry using the dye exclusion binary system propidium iodide (PI) - Syto 61. Compared with traditional CFU counting method, flow-cytometry is a cultivation-independent method allowing the consideration of non-cultivable bacteria. For flow-cytometry method, we used the dye exclusion binary system propidium iodide (PI)-Syto61 (Nebe-von-Caron et al., 2000). Syto61 dye binds directly nucleic acid allowing the detection of bacterial cells (living and dead) versus inert particles. PI exclusion dye penetrates cell membrane of damaged cells, while being excluded from living cells, allowing the specific detection of dead cells. After staining, single bacterial cells were directed through a tiny flow and individually exposed to a laser beam. Resulting fluorescent light emitted by the dyes PI and/or Syto61 is monitored, and used to characterize the viable state of the cell. Addition of the signal from a large number of cells allowed the determination of the ratio viable/dead cells. Flow-cytometry analyses were conducted at the Flow-cytometry Core Facility (WVU School of Medicine) using a BD FACStar Plus flow cytometer (Becton-Dickenson).

\subsubsection{Sample preparation for flow-cytometry}

The binary dye stock solution was prepared by mixing sterile and $2-\mu \mathrm{m}$ filtered PBS (1x), PI (10 $\left.\mathrm{mg} \mathrm{mL}^{-1}\right)$, and Syto61 in the ratio: 44:5:1. Aliquots of bacterial suspension were collected and $5 \mu \mathrm{L}$ of dye stock solution were added per $0.5 \mathrm{~mL}$ of sample. The resultant 
Chapter 3: Materials and Methods

mixture was incubated for 15 min at room temperature, and then analyzed by the flow-cytometry system.

\subsubsection{Flow-cytometry sorting}

For further investigation of the bacteria community structure, bacteria suspension samples were sorted in order to separated dead and living cells. Upon detection of the right combination of fluorescent color from the binary dye system, cells were sorted as living and dead cells and delivered in separated tubes. Dead and living cells were then used for DNA extraction and further characterization of the bacterial community structure using T-RFLP analysis.

\subsection{Bacterial Identification and Characterization of Microbial Community Structure}

\subsubsection{Identification of Isolated Pure Bacterial Strains by Genomic Fingerprinting}

\subsubsection{DNA extraction}

Total DNA was extracted using DNeasy ${ }^{\circledR}$ Tissue Mini Kit (Qiagen, Valentia, CA) using the modified protocol for Gram+ bacteria. DNA extracts were quantified by the absorbance at $260 \mathrm{~nm}$ and stored at $-80^{\circ} \mathrm{C}$. The quality of the DNA was assessed by agarose gel electrophoresis (AGE). When necessary, DNA was concentrated by ethanol precipitation using standard protocols (Ausubel et al., 1999).

\subsubsection{16S rDNA amplification}

PCR amplification of 16S rDNA was performed on a MasterCycler Gradient ${ }^{\circledR}$ thermocycler (Eppendorf, Westbury, NY) using HotStarTaq ${ }^{\circledR}$ Master Mix Kit (Qiagen, Valentia, CA) and the bacterial universal primers, $27 \mathrm{f}$ and 1492r. Cycling conditions were: Initial activation/denaturation at $95{ }^{\circ} \mathrm{C}$ for $15 \mathrm{~min} ; 30$ cycles: Denaturation at $95{ }^{\circ} \mathrm{C}$ for 1 min, annealing for $1 \mathrm{~min}$, and extension at $72{ }^{\circ} \mathrm{C}$ for $1.5 \mathrm{~min}$; and final extension at $72{ }^{\circ} \mathrm{C}$ for $10 \mathrm{~min}$. PCR products were analyzed by agarose gel electrophoresis (AGE). PCR amplification of $16 \mathrm{~S}$ rDNA was performed on a MasterCycler Gradient ${ }^{\circledR}$ thermocycler $^{-}$ (Eppendorf) using HotStarTaq ${ }^{\circledR}$ Master Mix Kit, bacterial universal primers (27 Forward and 1492 Reverse) (27f: 5'-AGAGTTTGATCCTGGCTCAG-3'; 1492r:

5'-GGTTACCTTGTTACGACT-3'. (Baker et al., 2003) (Integrated DNA Technologies, 
Coralville, IA), and total DNA extracts as template.

\subsubsection{DNA sequencing and related analysis}

16S rDNA PCR products were purified and sequenced by Sanger-based fluorescent identification of bases on an ABI 3700 electrophoresis detector. Bacterial and Archaeal species were identified by comparison of their DNA sequences with public genomic databases, NCBI (www.ncbi.nlm.nih.gov/) and RDPII, (http://rdp.cme.msu.edu/). For phylogenetic analyses, sequences were aligned using ClustalW Multiple Alignment (BioEdit, v5.0.9; www.mbio.ncsu.edu/BioEdit/bioedit.html). Tree topology was inferred by the "neighbor-joining" method using ClustalX (v1.83; ftp://ftp-igbmc.u-strasbg.fr/pub/ClustalX/) and Treeview (v1.6.6; taxonomy.zoology.gla.ac.uk/rod/treeview.html).

\subsubsection{Characterization of complex microbial community structure}

Cultivation techniques for analyzing the composition of the microbial community in an ecosystem are known to largely underestimate the diversity of organisms (only about $10 \%$ of microbes are cultivable under artificial conditions). On the opposite, molecular analysis based on DNA allows to obtain a more comprehensive description of the microbial diversity. Complex microbial community from activated sludge bacteria was then analyzed using PCR-based techniques. Bacterial species were identified using 16S rDNA as phylogenetic marker (Woese et al., 1990). Total DNA was extracted from samples and amplified by PCR. 16S rDNA amplicons profiles were analyzed by different methods, including terminal-restriction fragment length polymorphism (T-RFLP), and construction of clone libraries. Phylogenetic analysis of the microbial community was conducted using resources of bioinformatics and public genomic databases.

\subsubsection{Construction and screening of a gene library}

For each 16S rDNA pool, a clone library was constructed using TOPO TA Cloning ${ }^{\circledR}$ Kit (Invitrogen, Carlsbad, CA): Purified 16 rDNA amplicons was inserted in a vector plasmid and amplified in E. coli competent cells. A statistically representative number of clones in the library were cultivated in antibiotic selective medium and plasmids were extracted 
using QIAprep ${ }^{\circledR}$ Miniprep Kit (Qiagen). Inserts were re-amplified by PCR using primers M13 and digested using restriction enzymes HaeIII (20 U/rxn) and HhaI (20 U/rxn) (New England Biolabs, Beverly, MS). Digested fragments were analyzed by AGE and one member of each clone was sequenced (Davis Sequencing, Davis, CA) and search against public databases (http://www.ncbi.nlm.nih.gov/ and http://rdp.cme.msu.edu/).

Also after sorting by flow-cytometry, genomic library was applied to the sorting cells of bacteria to draw a profile of the microbial community distribution for both dead and living cells communities.

\subsubsection{Terminal-Restriction Fragment Length Polymorphism (T-RFLP) Analysis}

Genomic fingerprinting of a population of genes amplified using group-specific primers, for example, gene specific to a particular pathogen. For T-RFLP, PCR amplification using a specific primer labeled with a fluorescent molecule (FAM): (e.g., 5'-/56-FAM/ AGAGTTTGATCCTGGCTCAG-3' (Integrated DNA Technologies, Coralville, IA)) In addition, digestion by restriction enzymes targets specific DNA pattern at different locations. Each gene produces secondary fragment population with one particular terminal which is labeled. Therefore, after sequencing the terminal fragments by a DNA sequencer, different signal peaks were detected for sorts of bacteria species.

16S rDNA for TRF analysis was amplified with the "universal" primers $27 \mathrm{f}$ fluorescently labeled at 5'-end with FAM and 1492r. PCR amplification was carried as previously described except that a final cycle of annealing at $55{ }^{\circ} \mathrm{C}$ for $1 \mathrm{~min}$ was added. Three independent PCRs were performed for each sample; PCR products were pooled and purified using QiaQuick ${ }^{\circledR}$ PCR Purification Kit (Qiagen). Purified amplifications were digested separately with the restriction enzymes: HaeIII (Target 5'...GG-CC...3'), RsaI (Target 5'...GT-AC...3') and AluI (Target 5'...AG-CT...3') (New England Biolabs, Ipswich, MA), and incubated in $37^{\circ} \mathrm{C}$ water bath for $3 \mathrm{~h}$, then, another $20 \mathrm{~min}$ in $65^{\circ} \mathrm{C}$. Fragment profiles were analyzed by AGE electrophoresis. Digested fluorescent amplification products $(0.1$ to $0.5 \mu \mathrm{L})$ were mixed with $0.5 \mu \mathrm{L}$ ROX-1000 DNA Size Standard (Applied Biosystems, Foster City, CA) and $9 \mu \mathrm{L}$ DI formamide and analyzed by 
capillary electrophoresis with an ABI 377 DNA sequencer (Applied Biosystems) (Dunbar et al., 2000).. Mixtures were load in 96-well microplates, denatured in $95^{\circ} \mathrm{C}$ for $3 \mathrm{~min}$ in a thermocycler. Plates were then shortly centrifuged at 1,500 rpm.

TRF sizes were determined using Genescan v2.0.2 and GeneMapper v4.0 software (Applied Biosystems). Statistical analysis of TRF data was performed following the method developed by Abdo et al. (2006). Sample ordination was performed using principal components analysis (PCA) on covariance matrices to determine the variation in microbial community. Relative abundance data of the TRF was analyzed separately using SAS v4.0.4. statistical software package (Benitez et al., 2007). DNA was extracted from cells after sorting by flow-cytometry using 5'-FAM-labeled universal primers as described above.

\subsection{High Performance Liquid Chromatography (HPLC) Analysis}

The bacteria suspensions were treated using different method to identify the distribution of Triclosan in the different fractions of bacterial suspensions. Analysis of Triclosan was conducted using HPLC. Four methods were used to prepare the samples in this experiment:

Simple centrifugation: Samples were centrifuged at 13,200 rpm for 10min, and the supernatants were collected, mixed with equal volume of acetonitrile, filtered on $0.2 \mu \mathrm{m}$, and introduced into auto-sample tubes.

Lysozyme treatment: Lysozyme buffer (Tris-EDTA (10x) $0.5 \mathrm{ml}$ into $2 \mathrm{ml}$ D.I. water, triton 100x one drop (1.2\%) and $50 \mathrm{mg}$ lysozyme For 12 samples) was added and mixed to enzymatic lysate of bacterial cells, and the bacterial suspensions were incubated in $37^{\circ} \mathrm{C}$ water bath for at least $40 \mathrm{~min}$ and then treated as centrifugation method.

Extraction with acetonitrile: Acetonitrile was added into the bacterial suspensions to a ratio $1: 1 \mathrm{v} / \mathrm{v}$. Resulted mixtures were strongly vortexed for $30 \mathrm{~min}$ to remove Triclosan potentially adsorbed on the surface of bacterial cells. The supernatants were collected after centrifugation, filtered on $0.2 \mu \mathrm{m}$, and introduced into auto-sample tubes. 
Chapter 3: Materials and Methods

Sonication: bacterial suspensions were continually vigorously sonicated for $10 \mathrm{~min}$ in ice-water system, centrifuged, filtered on $0.2 \mu \mathrm{m}$, and introduced into auto-sample tubes. Vigorous sonication was expected to break the cell wall in order to access Triclosan potentially taken up inside cells and/or physical adsorbed onto cells.

Triclosan was then analyzed by reverse phase HPLC using a HP Series 1100 (Hewlett-Packard, Palo Alto, CA) on a $\mathrm{C}_{18}$ Supelcosil LC-18 column (Supelco, Bellefonte, PA). The HPLC standard curve of Triclosan concentration was drawn by analyzing standard Triclosan solutions from $0-50 \mathrm{mg} \mathrm{L}^{-1}$. The standard curve was shown in Figure 3.1.

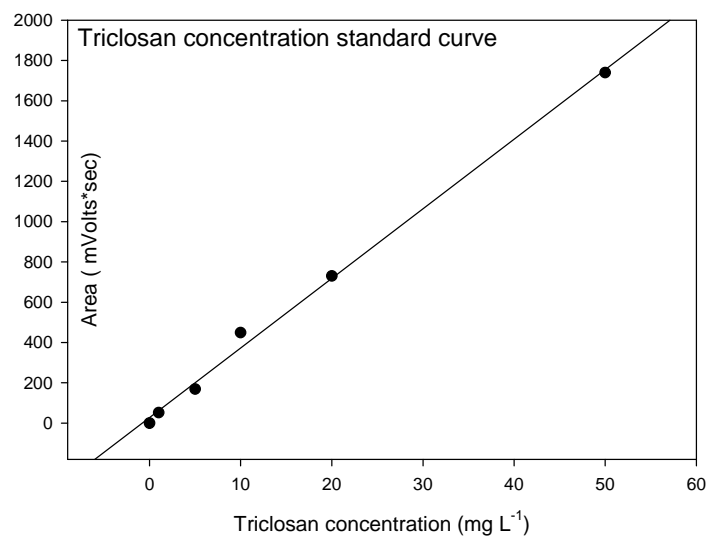

Figure 3.1: Triclosan concentration standard curve of HPLC analysis.

Table 3.1: Gradient method of HPLC analysis for Triclosan

\begin{tabular}{lll}
\hline & \multicolumn{2}{c}{$10 \mu \mathrm{L}$ volume injection of sample } \\
\hline Time (min) & Solution percentage of A (water) & Solution percentage of B (acetonitrile) \\
\hline $0: 00$ & 50 & 50 \\
$8: 00$ & 10 & 90 \\
$12: 00$ & 10 & 90 \\
$13: 00$ & 50 & 50 \\
$16: 00$ & 50 & 50 \\
\hline
\end{tabular}

The mobile phase was a gradient system of acetonitrile: $\mathrm{H}_{2} \mathrm{O}$ operating at $50 \%$ 
Chapter 3: Materials and Methods

acetonitrile for $8 \mathrm{~min}$, from 10 to $90 \%$ acetonitrile in $4 \mathrm{~min}$, from $50 \%$ acetonitrile in 1 $\mathrm{min}$, and hold at $50 \%$ for $3 \mathrm{~min}$, at a flow rate of $1.0 \mathrm{~mL} \mathrm{~min}^{-1}$, specific operating conditions are detailed in Table 3.1. Triclosan was detected by its absorbance at $254 \mathrm{~nm}$. 
Chapter 4: Results and discussion

\section{Chapter 4: Results and Discussion}

\subsection{Specific Aim 1}

Investigation of the hypothesis, that exposure to Triclosan will modify the susceptibility of activated sludge bacteria to chlorination and UV, was processed with the sludge bacteria communities.

\subsubsection{Effect of Triclosan on bacterial growth of activated sludge bacteria}

The first step in our experimental scheme was to determine the susceptibility of activate sludge bacteria to Triclosan. A complex bacterial mixture from an activated sludge was therefore exposed to increasing concentrations of Triclosan and incubated in agitated batches. Bacterial growth was monitored by the regular collection of cell suspensions and the measurement of the optical density at $600 \mathrm{~nm}$. After $48 \mathrm{~h}$, aliquots of the cell suspensions were collected and used to start the sub-cultures. Bacteria were sub-cultured two times in the presence of Triclosan for acclimation (i.e., a total of three cultures).

Figure 1 shows the growth curves of the bacterial suspensions during the three (sub-) cultures as measured by the O.D. at $600 \mathrm{~nm}$.

Exposure to Triclosan resulted in a decrease of the rate of growth in a concentration-dependent fashion, even though a positive growth was still observed at the highest level $\left(20 \mathrm{mg} \mathrm{L}^{-1}\right)$. Also the lag phase was significantly reduced after the first exposure, indicating acclimation of bacteria on Triclosan. These results are consistent with previous reports. For instance, studying the effect of Triclosan on 11 different bacterial strains, McBain et al. (2004) reported Triclosan minimum inhibitory concentrations (MIC) ranging from 0.1 to $21 \mathrm{mg} \mathrm{L}^{-1}$. The authors also observed that previous exposure to Triclosan resulted in a higher resistance in 7 out of the 11 strains tested. Acclimated strains were resistant to up to $39 \mathrm{mg} \mathrm{L}^{-1}$ Triclosan. And similarly, Pumbwe et al. (2006) indicated that antimicrobial MIC of Triclosan to Bacteroides fragilis increased significantly (up to $62.8 \mathrm{mg} \mathrm{L}^{-1}$ ) after selection in Triclosan. 
Chapter 4: Results and discussion

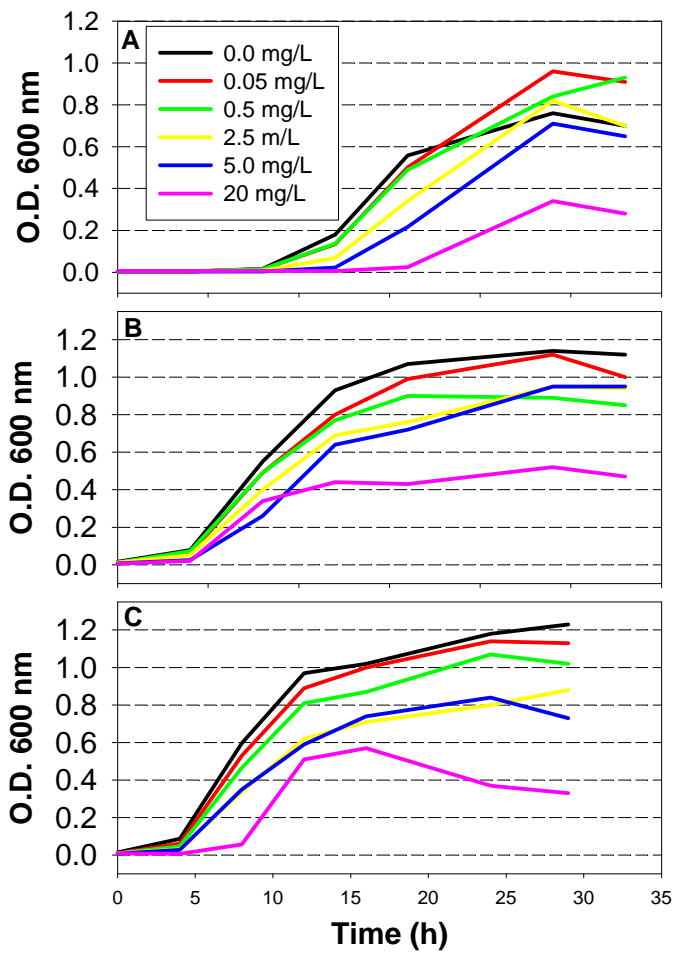

Figure 4.1: Growth curves of activated sludge bacterial suspensions exposed to different concentrations of Triclosan, as measured by the optical density (O.D.) at $600 \mathrm{~nm}$ : (A) Initial culture, (B) 1st sub-culture, (C) 2nd sub-culture.

\subsubsection{Effect of the acclimation on Triclosan on the susceptibility of activated sludge bacteria to chlorination}

In order to determine whether exposure to Triclosan can induce bacterial changes, including a potential decrease of susceptibility to disinfectants, which would raise concerns for public health, chlorination experiments were conducted on activated sludge bacterial mixture and pure cultures previously acclimated on different concentrations of Triclosan.

A control, non-exposed activated sludge bacterial suspension was first treated with increasing doses of chlorine (from 0.0 to $25 \mathrm{mg} \mathrm{L}^{-1} \mathrm{~min} \mathrm{Cl}$ ) in order to determine sub-lethal doses being used in further disinfection experiments. Bacterial survival numbers were determined by flow-cytometry and CFU counting (Figure 4.2). The results 
show that chlorine concentrations above $1.0 \mathrm{mg} \mathrm{L}^{-1} \mathrm{~min} \mathrm{Cl}$ exerted a significant effect on the bacterial growth. However, even very high concentrations of chlorine (up to $25 \mathrm{mg}$ $\mathrm{L}^{-1} \min \mathrm{Cl}$ ) did not fully inhibit bacterial growth. To test further the effect of Triclosan acclimation on susceptibility to chlorine, cell suspensions were exposed to a sub-lethal dose of $5.0 \mathrm{mg} \mathrm{L}^{-1}$. Typically only 1 to $15 \%$ of bacteria from activated sludge are cultivable, therefore cell viability was tested using in parallel direct colony counting and flow-cytometry, which is a culture-independent technique.

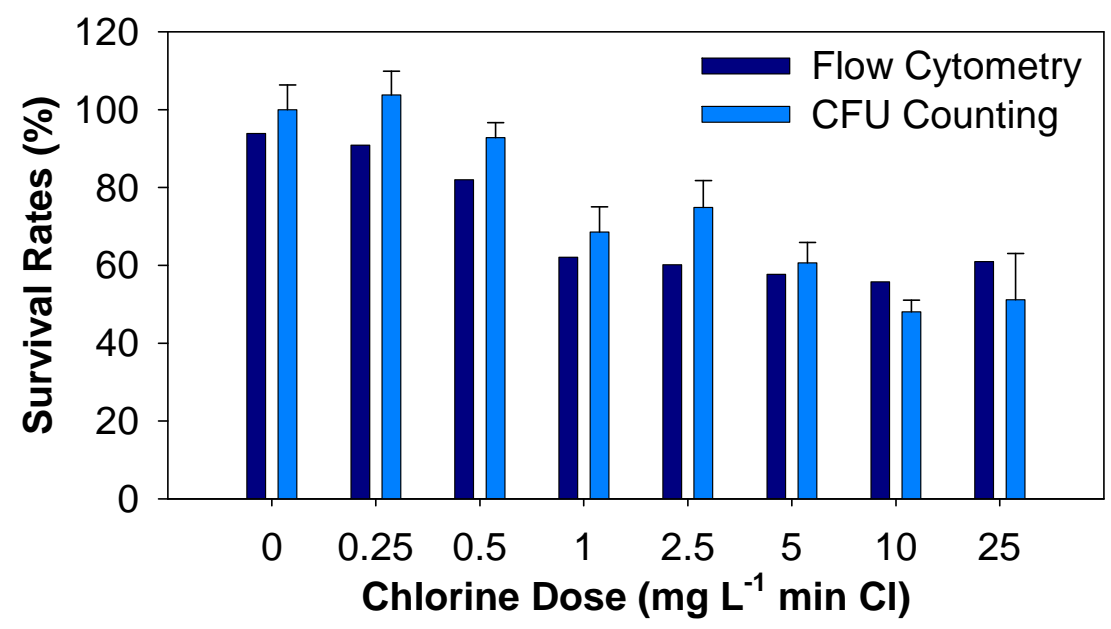

Figure 4.2: Survival rates of activated sludge bacteria exposed to increasing concentrations of chlorine $(\mathrm{NaClO})$, as measured by flow-cytometry and by plating and CFU counting.

Activated sludge bacterial suspensions acclimated in the presence of different concentrations of Triclosan $\left(0.0,0.5,2.5\right.$, and $\left.20 \mathrm{mg} \mathrm{L}^{-1}\right)$ were exposed to a sub-lethal dose of chlorine $\left(5.0 \mathrm{mg} \mathrm{L}^{-1} \mathrm{~min} \mathrm{Cl}\right)$. Bacterial survival rates were again determined by flow-cytometry and by CFU counting (Figure 4.3, 4.4 and 4.5). The results showed that acclimation on Triclosan dramatically increased the susceptibility of activated sludge bacteria to chlorination. Especially from Figure 4.4, a sighnificant shift shew between non exposed and exposed communities. This can be explained by a change of the bacterial community structure toward strains less resistant to chlorine, or by physiological 
changes in bacterial cells, or both. Although some bacteria species can survive even after exposure to lethal concentrations, acclimation to Triclosan may have modified the permeability of survival cells by modifying the cell wall structure and/or composition (Hay 2001; Schweizer et al., 2001; Yazdankhah et al., 2006). It is conforting to note that the two methods for determination of cell survival numbers, plating and flow-cytometry, showed similar patterns, suggesting that the effect of Triclosan on the susceptibility to chlorine was comparable in cultivable and non-cultivable bacteria.
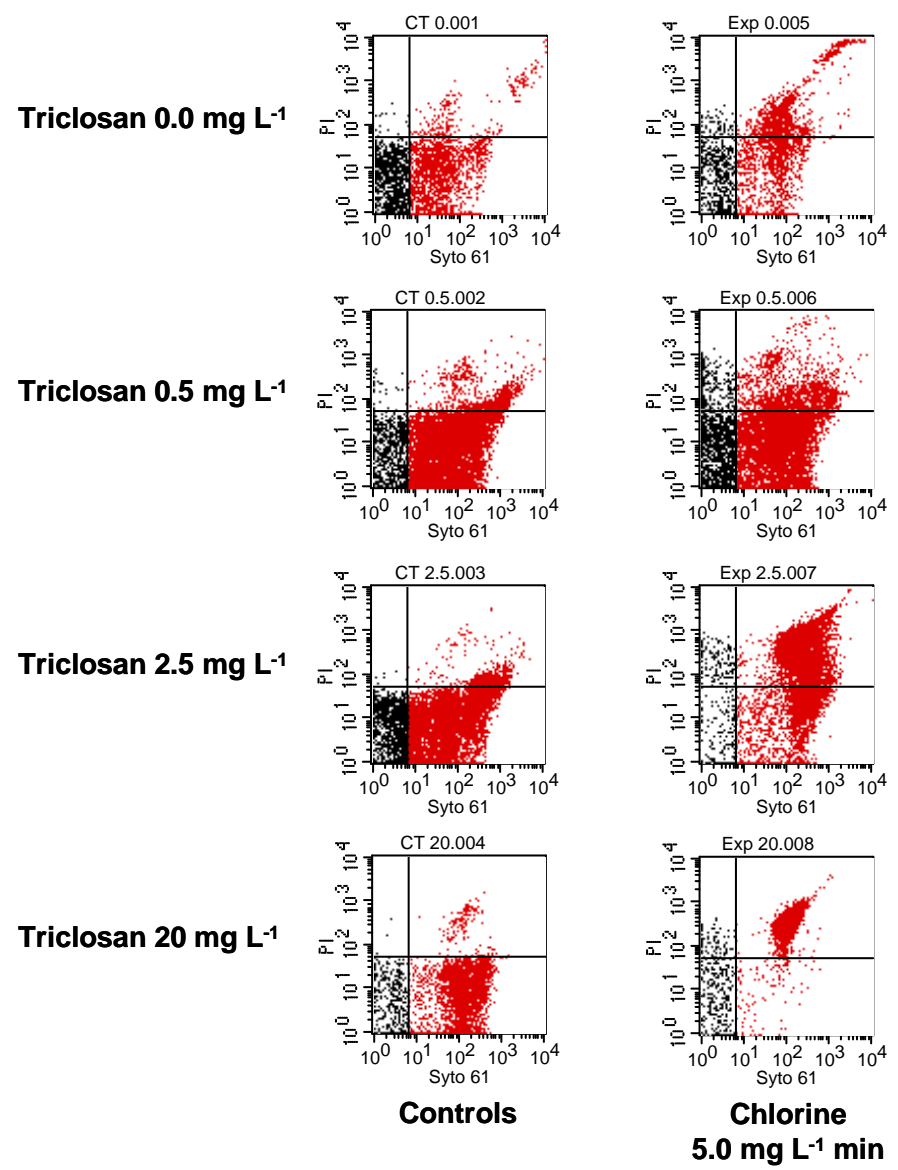

Figure 4.3: Cell viability assay by flow-cytometry: Effect of chlorination on activated sludge bacteria previously acclimated by repeated sub-cultivation in the presence of Triclosan: $0.0,0.5,2.5$, and $20 \mathrm{mg} \mathrm{L}^{-1}$. Left: Control non-exposed to chlorine. Right: Cultures exposed to chlorine $500 \mathrm{mg} \mathrm{L}^{-1} \mathrm{~min}$. 
Chapter 4: Results and discussion
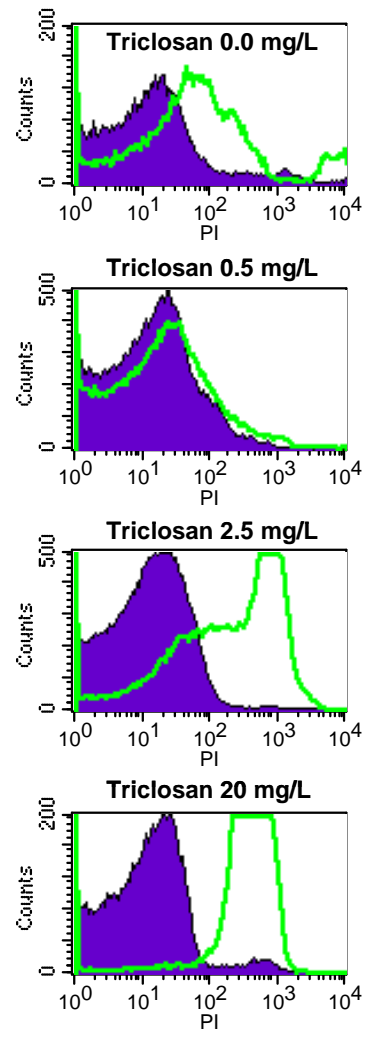

Figure 4.4: Cell viability assay by flow-cytometry: Effect of chlorination on activated sludge bacteria previously acclimated by repeated sub-cultivation in the presence of Triclosan: 0.0, 0.5, 2.5, and $20 \mathrm{mg} \mathrm{L}^{-1}$. Blue area: Control non-exposed to chlorine. Area below green: Cultures exposed to chlorine $500 \mathrm{mg} \mathrm{L}^{-1} \mathrm{~min}$. 


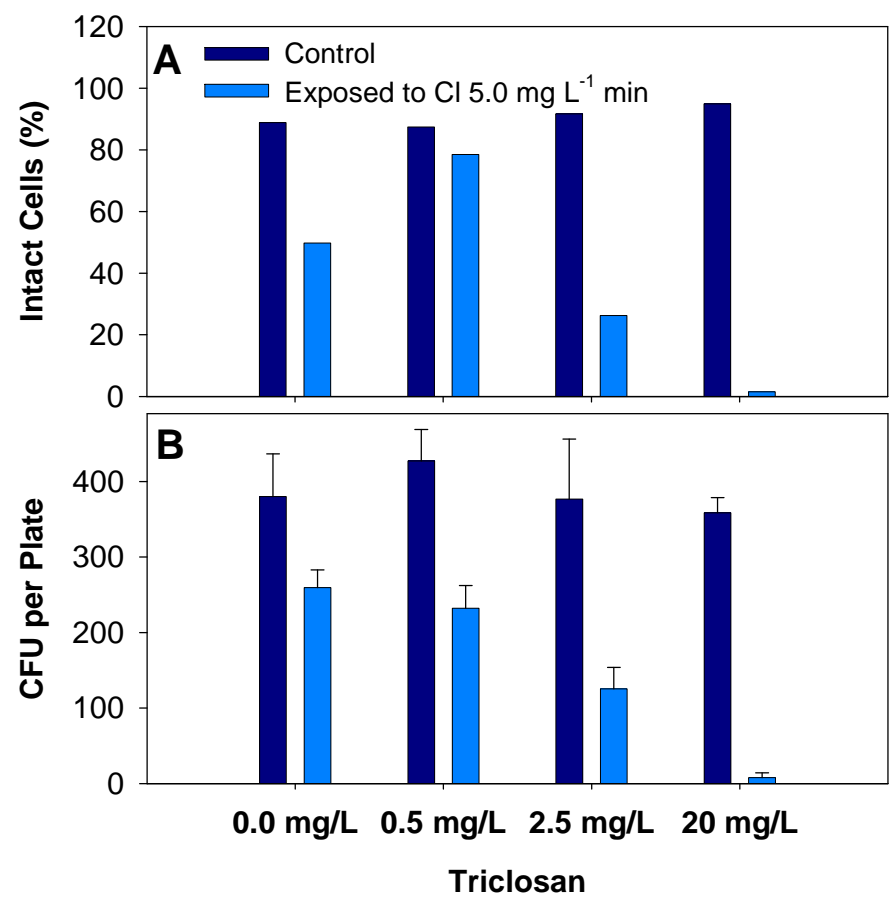

Figure 4.5: Survival rates of activated sludge bacteria acclimated on increasing concentrations of Triclosan and exposed to $5.0 \mathrm{mg} \mathrm{L}^{-1}$ min of chlorine, as measured by flow-cytometry and CFU counting.

\subsubsection{Effect of Triclosan on bacterial susceptibility to UV}

In order to investigate whether Triclosan acclimation can induce bacterial changes, leading to a potential decrease of susceptibility to disinfectants, and compare the differences between effects of Triclosan acclimation on the susceptibility of bacteria to different disinfectants, UV experiments were conducted on activated sludge bacterial mixture previously acclimated on different concentrations of Triclosan.

In order to determine the sub-lethal dose being used in further disinfection experiments, a non-exposed bacterial suspension was first treated with increasing doses of UV (from 0.0 to $200 \mathrm{~mJ} \mathrm{~cm}{ }^{-2}$ ). Bacterial susceptibility to UV was assessed by plating and CFU counting. Figure 4.6 shows that a dose of $5.0 \mathrm{~mJ} \mathrm{~cm}^{-2}$ significantly impacted cells, while a dose of $100 \mathrm{~mJ} \mathrm{~cm}^{-2}$ was necessary to fully inhibit bacterial growth. To test further the 
Chapter 4: Results and discussion

effect of exposure to Triclosan on susceptibility to UV, cell suspensions were exposed to a sub-lethal dose of $2.5 \mathrm{~mJ} \mathrm{~cm}^{-2}$. Flow-cytometry was not used to detect UV-exposed cells. Flow-cytometry cell viability analyses were based on the exclusion dye, propidium iodide, which penetrates only damaged cells. UV irradiation is known to impact primarily DNA and does not affect significantly the membrane structure, therefore preventing detection by flow-cytometry.

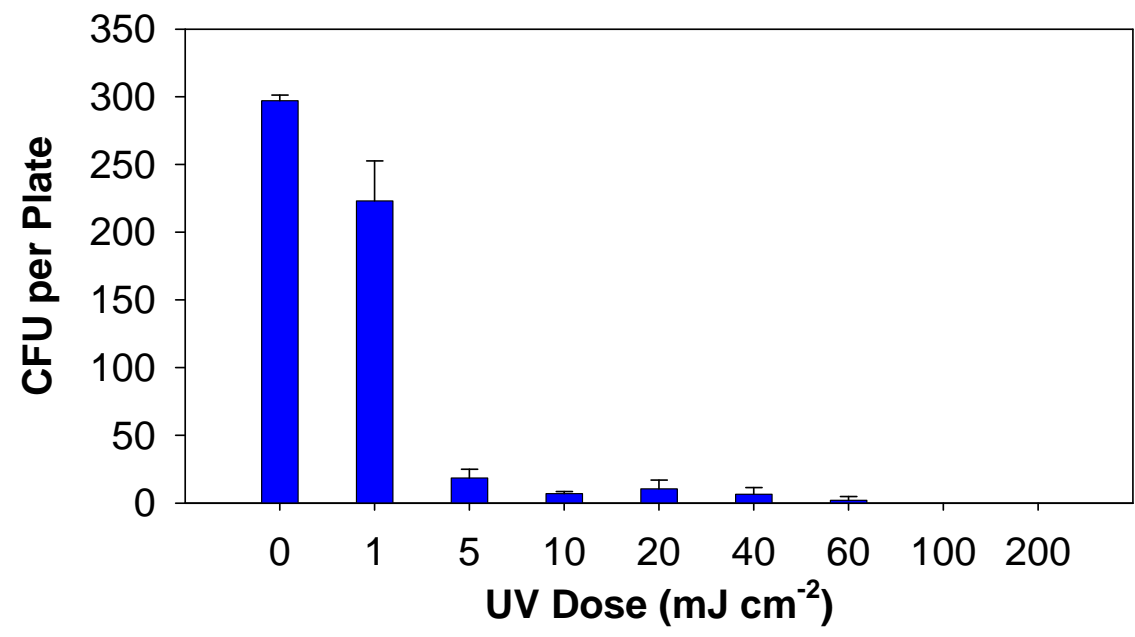

Figure 4.6: Effect of UV irradiation (low-pressure UV, $254 \mathrm{~nm}$ ) on the survival of bacteria of an activated sludge, as measured by plating on solid medium and CFU counting.

Activated sludge bacteria sub-cultured three times in the presence of increasing concentrations of Triclosan $\left(0.0,0.5,2.5\right.$, and $\left.20 \mathrm{mg} \mathrm{L}^{-1}\right)$ were exposed to a sub-lethal dose of UV ( $\left.2.5 \mathrm{~mJ} \mathrm{~cm}^{-2}\right)$. Bacterial survival rates were determined by plating on synthetic sewage feed and CFU counting (Figure 4.7). The results showed that acclimation on the highest dose of Triclosan $\left(20 \mathrm{mg} \mathrm{L}^{-1}\right)$ increased the susceptibility of activated sludge bacteria to UV irradiation. However, acclimation to 0.5 to $2.5 \mathrm{mg} \mathrm{L}^{-1}$ did not modify significantly cell susceptibility, as compared with non-exposed cells. As observed previously with chlorination, this result can be explained by a change of the bacterial community structure and/or by physiological changes of the cells. 


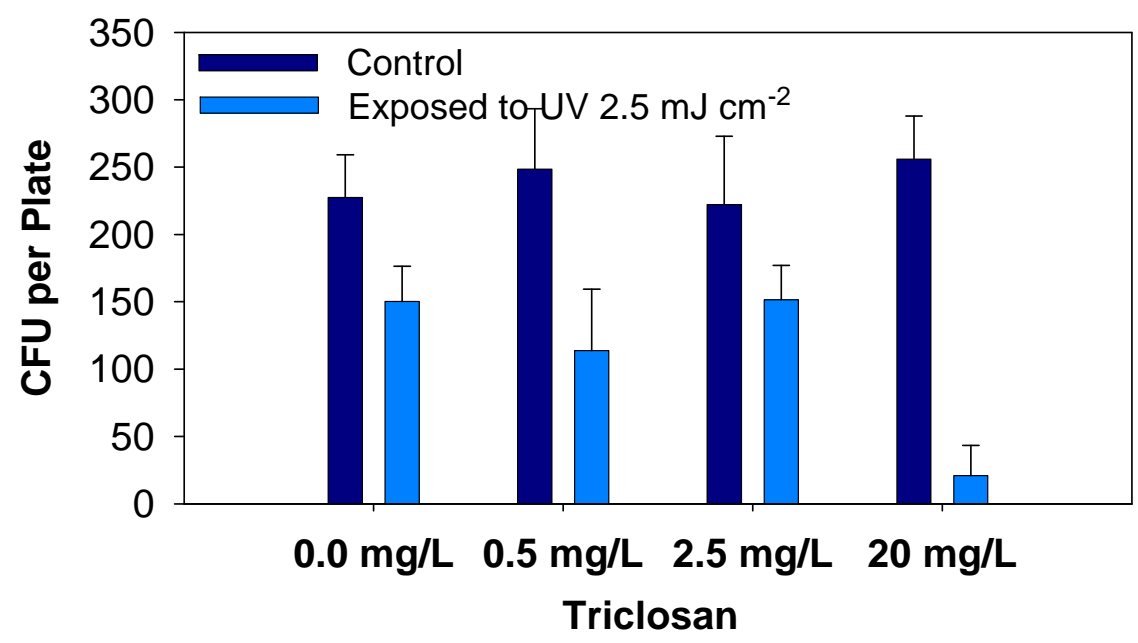

Figure 4.7: Survival rates of activated sludge bacteria acclimated to increasing concentrations of Triclosan and exposed to UV irradiation at $2.5 \mathrm{~mJ} \mathrm{~cm}^{-2}(254 \mathrm{~nm})$, as measured by plating and CFU counting.

Chlorination affects microorganisms primarily through the strong oxidation property of its hydrolysis and dissociation products, hypochlorous acid and hypochlorite (Fairs et al., 1948). UV light applies energy to cell bio-molecules, especially nucleic acids, resulting in activated molecules that would undergo photochemical reactions, producing, for instance, base dimers (Rusin and Gerba, 2001). The factors that affect the susceptibility of bacteria to chlorination are believed to be the cell permeability and attachment to surfaces (Rusin and Gerba, 2001). On the other hand, UV light sensitivity of bacteria depends on several factors, such as the growth phase and the state of the life cycle (Rusin and Gerba, 2001). Mason and Setlow (1986) found that spore-producing bacteria are more resistant to UV disinfection. It is suggested that, after exposure to Triclosan, which inhibited the reproduction of bacteria cells, the susceptibility of bacteria can be increased. Similarly, Lambert et al., (2002) indicated that a synergy between antimicrobial agents exists and could significantly improve the efficiency of antimicrobial activities. In addition, Murphy et al., (2008) reported a similar synergy phenomenon between disinfectants, such as UV and chlorination. 
Chapter 4: Results and discussion

\subsection{Specific Aim 2}

The determination of the origin of the change in susceptibility observed in Specific Aim 1 was performed through two different steps:

\section{$\underline{\text { Sub-Aim 1: }}$}

To test if the observed change in susceptibility can be explained by a shift in the microbial community structure.

\subsubsection{Investigation of the effect of Triclosan on bacteria community structure using genomic library}

In order to test the hypothesis that acclimation on Triclosan would affect the community structure, potentially explaining the observed increase of susceptibility to disinfection, the bacterial community was analyzed using RFLP. Two clone libraries were constructed, the first from a control, non-exposed bacterial mixture and the second from a mixture sub-cultured three times in the presence of $20 \mathrm{mg} \mathrm{L}^{-1}$ Triclosan. Table 4.1 shows that exposure to Triclosan resulted in a significantly lower bacterial diversity, as compared to the non-exposed culture: 31 different strains out of a total of 78 colonies analyzed have been isolated from the control mixture and only 5 different strains out of a total of 50 colonies have been isolated from the Triclosan-acclimated sludge. The Shannon diversity index was 2.76 for the non-exposed culture and 1.45 for the Triclosan-acclimated culture. The two major strains detected in the activate sludge acclimated on Triclosan were isolated and cultivated in the lab as pure cultures. The strains were further identified by 16S rDNA fingerprinting as P. fluorescens and S. marcescens.

Similarly, McBain et al. (2003) observed a reduction of the microbial diversity of a wastewater microcosm upon exposure to Triclosan. The authors also identified Triclosan-resistant strains in the groups of pseudomonads and stenotrophomonads. It is interesting to note that our two isolates from Triclosan-acclimated activated sludge are the same Triclosan-resistant strains that were previously isolated from a food processing facility (Moretro et al., 2006). By its antimicrobial properties, exposure to Triclosan can potentially modify cell properties, such as wall and membrane composition, possibly 
Chapter 4: Results and discussion

increasing susceptibility to disinfection. Particularly, the physiological action of Triclosan is the inhibition of the enoyl-acyl carrier protein reductase (ENR), a key enzyme involved in the membrane fatty acids biosynthesis (Yazdankhah et al., 2006). However this effect can be masked by a change in the microbial community structure (McBain et al., 2003). According to our results, the increase of bacterial susceptibility after acclimation on Triclosan can be explained, at least partly, by a change of the microbial community structure.

Table 4.1: Bacterial strains identified from a control, non-exposed activated sludge mixture and a mixture acclimated on $20 \mathrm{mg}$ L-1 Triclosan

\begin{tabular}{llllll|ll}
\hline \multicolumn{2}{l}{ Non-Exposed Activated Sludge } & & & & & \multicolumn{2}{l}{ Acclimated on Triclosan } \\
\hline Genus & $\#$ & Genus & $\#$ & Genus & $\#$ & Genus & $\#$ \\
\hline Pseudomonas \#1 & 21 & Janthinobacterium & 1 & Blastobacter & 1 & Serratia \#2 & 14 \\
Pseudomonas \#2 & 13 & Crocinitum & 1 & Nostoc & 1 & Pseudomonas \#6 & 14 \\
Comamonas & 6 & Alysiella & 1 & Xenohaliotis & 1 & Stenotrophomonas \#2 & 11 \\
Acinetobacter \#1 & 4 & Trichoccocus & 1 & Salmonella & 1 & Providentia & 10 \\
Flavobacterium & 3 & Phyllobacterium & 1 & Serratia \#1 & 1 & Caulobacter & 1 \\
Stenotrophomonas \#2 & 3 & Pseudomonas \#5 & 1 & Raoultella & 1 & & \\
Sphingobacterium & 3 & Stenotrophomonas & 1 & Ralstonia & 1 & & \\
Lactobacillus & 2 & Ruminococcus & 1 & Caulobacter & 1 & & \\
Aeromonas & 1 & Microvirgula & 1 & Ochrobactrum & 1 & & \\
Pseudomonas \#3 & 1 & Gloeothece & 1 & & & \\
Pseudomonas \#4 & 1 & Bergeyella & 1 & Total & $\mathbf{7 8}$ & Total \\
\hline
\end{tabular}

$\underline{\text { Sub-Aim 2: }}$

To test if the observed change in susceptibility can be explained by an induced tolerance of Triclosan-selected strains.

\subsubsection{Acclimated pure culture chlorination}

To further investigate the relative susceptibility of different members of the bacterial community, $P$. fluorescens and S. marcescens, two isolated Triclosan-resistant species, were chosen for pure culture chlorination experiment. After isolation, the two strains were cultured in the presence of different concentrations of Triclosan over successive sub-cultures for acclimation of the bacteria on Triclosan. As shown in Figure 4.8, even in 
Chapter 4: Results and discussion

the presence of very high concentrations of Triclosan, $P$. fluorescens and S. marcescens were growing efficiently.
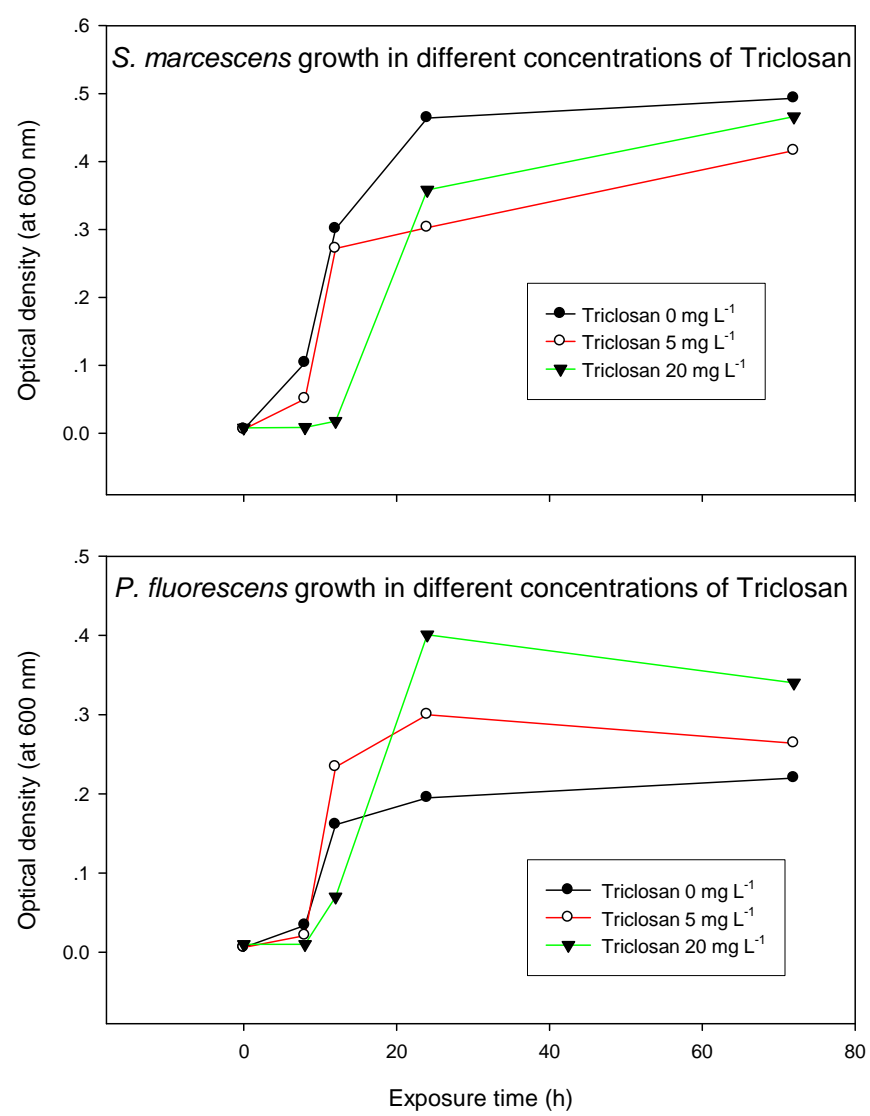

Figure 4.8: Growth of pure cultures $P$. fluorescens and $S$. marcescens cell suspensions exposed to increasing concentrations of Triclosan: $0.0,5.0$, and $20 \mathrm{mg} \mathrm{L}^{-1}$ measured by optical density at $600 \mathrm{~nm}$.

Figure 4.9 show that $S$. marcescens strain exhibits a higher resistance to chlorine after exposure to high concentrations of Triclosan. That indicates that exposure to Triclosan can potentially decrease the sensitivity of potential pathogenic strains to germicides, such as chlorine.

These results seem in opposition to chlorination experiments obtained earlier with mixed cultures. It may demonstrate that exposure to Triclosan selects strains which have high 
level resistance to antimicrobial agents. Sanchez et al. (2005) observed previously that exposure to Triclosan selected resistant mutants of another Triclosan-tolerant strain, Stenotrophomonas maltophilia (Moretro et al., 2006), which overexpressed the multidrug-resistance efflux pump gene, SmeDEF.

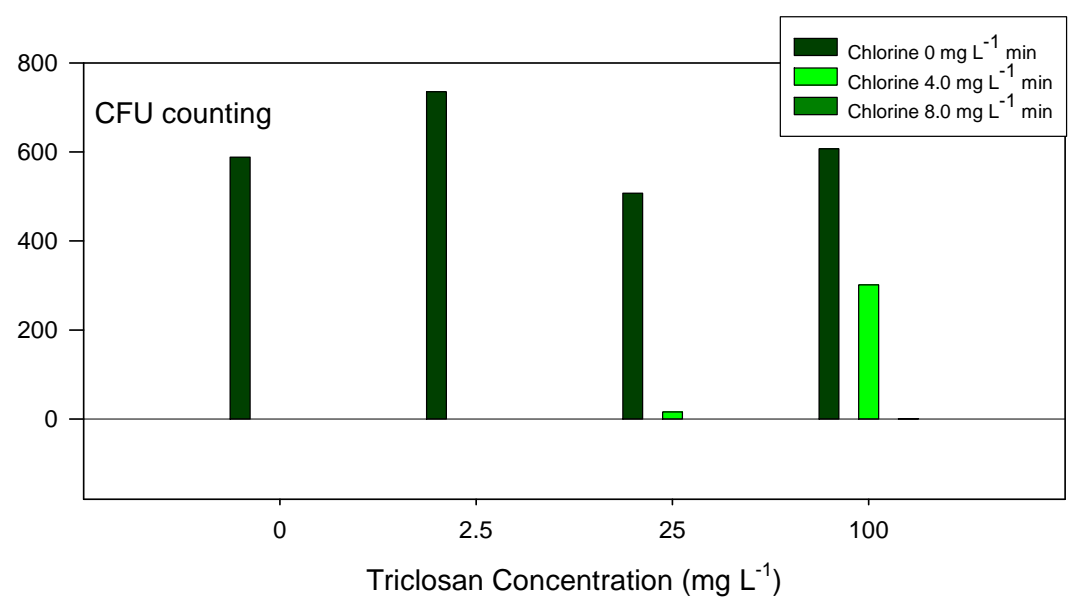

Figure 4.9: Chlorination sensitivity experiments using strain $S$. marcescens exposed to Triclosan 0, 2.5, 25 and $100 \mathrm{mg} \mathrm{L}^{-1}$. Chlorine concentration: 0, 4.0 and $8.0 \mathrm{mg} \mathrm{L}^{-1} \mathrm{~min}$.

\subsubsection{High Performance Liquid Chromatography (HPLC) analyses}

To investigate the mechanisms of the increasing of bacteria community susceptibility and the resistance of the two pure cultures to Triclosan and chlorination, HPLC analysis was performed to determine the Triclosan concentration in bacterial suspensions at different time points.

\subsubsection{Detection of Triclosan in activated sludge bacteria mixture acclimated to $\underline{\text { Triclosan }}$}

Samples were collected from Triclosan acclimated mix cultures, treated by regular centrifuge method, and then, mixed with acetonitrile. The resulting solutions were analyzed by HPLC.

As shown in Figure 4.10, there was a significant decreasing trend of Triclosan 
Chapter 4: Results and discussion

concentration with time before $12 \mathrm{~h}$ of exposure. However, a slight increase was observed at the end of the exposure time.

These results suggest that bacteria can reduce the concentration of Triclosan in solution, either by biodegradation or by uptake inside the cells. Similar, Hay et al. (2001) observed that a few bacterial species were capable of mineralizing the aromatic ring of Triclosan as sole carbon source. Meade et al. (2001) indicated that Pseudomonas putida and Alcaligenes xylosoxidans can also metabolized Triclosan as the only carbon source. That means that after disinfection, the treated water released into the environment may contain Triclosan-biodegradation by-products, some of which being potentially more toxic than Triclosan (Orvos et al., 2002; McBain et al., 2003).

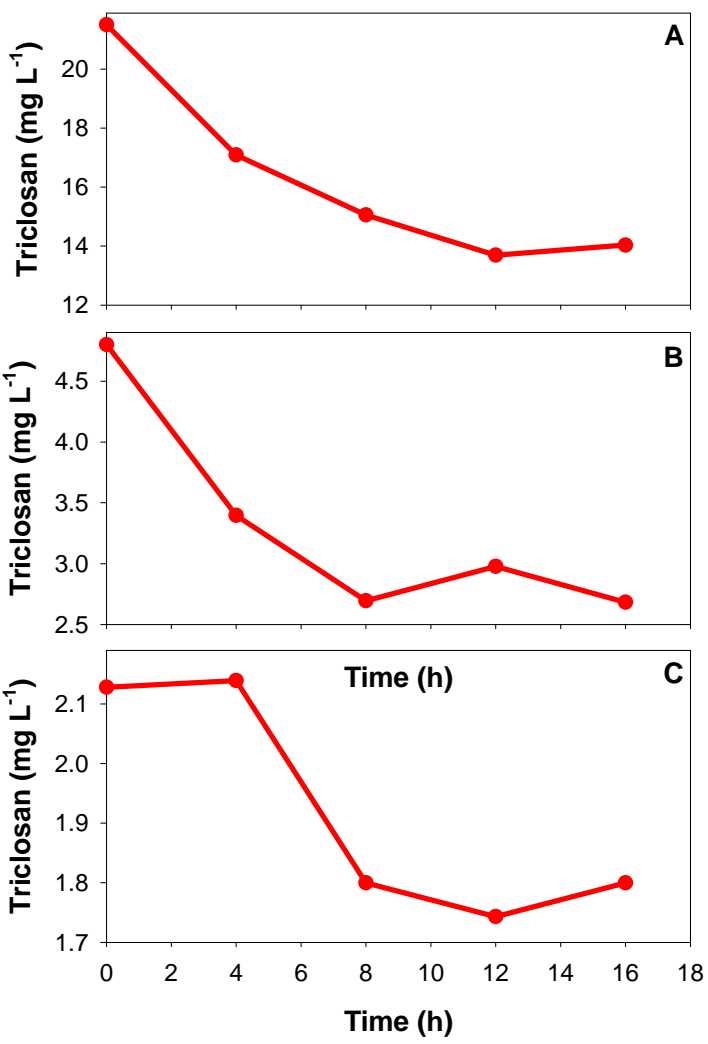

Figure 4.10: Concentration profile of Triclosan in activated sludge cultures exposed to 20 (A), 5 (B), and 2.5 (C) $\mathrm{mg} \mathrm{L}^{-1}$. 
Also from the slight increase of Triclosan concentration by the end of the experiment, it is suggested that other resistance mechanisms could exist than biodegradation, such as efflux pump system, and adsorption. In order to investigate if these mechanisms exist, HPLC analysis of Triclosan in the pure culture of two Triclosan-resistant pure strains, $P$. fluorescens and S. marcescens, was performed.

\subsubsection{Detection of Triclosan in Triclosan-resistant pure cultures}

The goal of this experiment was to investigate the fate of Triclosan in the presence of bacterial cells. Exposure of a bacterial suspension to lipophilic xenobiotic compounds can potentially result in adsorption onto bacterial cells or absorption into cells, possibly followed by enzymatic biodegradation inside the cells (Singer et al., 2002). Four different methods were applied on sample preparation to investigate the distribution of Triclosan outside and inside bacteria cells. The first method consisted in simple centrifugation in order to remove bacterial cells and detect the remaining Triclosan in the external liquid environment of cells; the second method consisted in acetonitrile extraction in order to remove Triclosan potentially adsorbed on the surface of cells; the third method consisted in lysozyme treatment in order to achieve enzymatic lysis of bacterial cells and access Triclosan potentially taken up inside cells; finally, the fourth method consisted in vigorous sonication in order to mechanically break the bacterial cells and access Triclosan potentially taken up inside cells.

As shown in Figure 4.11, the concentrations of Triclosan were similar using both simple centrifugation (first method) and vigorous sonication method (fourth method) with $P$. fluorescens and S. marcescens. For acetonitrile extraction of $P$. fluorescens cells, HPLC analysis detected more Triclosan than the other methods. For S. marcescens, lysozyme treatment detected the highest Triclosan concentration.

Acetonitrile extraction (second method) can significantly adsorb Triclosan on the cell external surface. On the other hand, the lysozyme treatment (third method) can dissolve the cell wall to set free Triclosan taken up inside the cell. 
These results indicate that Triclosan can adsorb on the surface of both strains. On the other hand, our results suggest that $S$. marcescens may have efflux pump systems as Triclosan resistance mechanism, confirming previous observations reported by Kumar and Worobec, (2002).

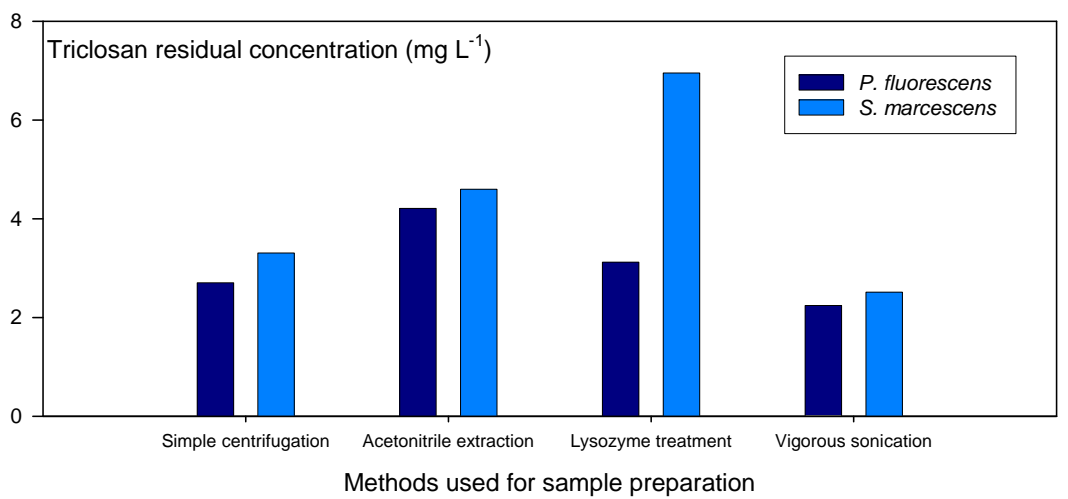

Figure 4.11: Concentration profile of Triclosan in P. fluorescens and S. marcescens cell suspension, after exposure to $20 \mathrm{mg} \mathrm{L}^{-1}$ of Triclosan for $48 \mathrm{~h}$. Samples were prepared by four different methods: Centrifugation, acetonitrile extraction, lysozyme treatment, and sonication, to investigate Triclosan residual in different fractions of the cell suspensions.

\section{3 $\underline{\text { Specific Aim } 3}$}

Further investigation of the relative susceptibility of different activated sludge members acclimated in the presence and in the absence of Triclosan was preceded in this step.

\subsubsection{Microbial Community: Terminal-restriction fragment length polymorphism}

\section{(T-RFLP) analysis}

The objective of this experiment was to determine the relative susceptibilities to chlorination of different Triclosan-acclimated and non-acclimated bacteria.

Triclosan-acclimated activated sludge bacterial suspensions were exposed to different levels of chlorination. Dead and alive cells were then sorted by flow-cytometry, DNA was extracted, and the bacterial community structure was investigated by terminal 
Chapter 4: Results and discussion

restriction fragment (TRF) analyses.

After cell sorting by flow-cytometry, the survival rates were calculated and normalized by the survival rates of non-exposed controls. As observed previously, Figure 4.12 shows that increasing Triclosan concentration resulted in a higher susceptibility of the activated sludge community to chlorination, as already observed earlier in this research.

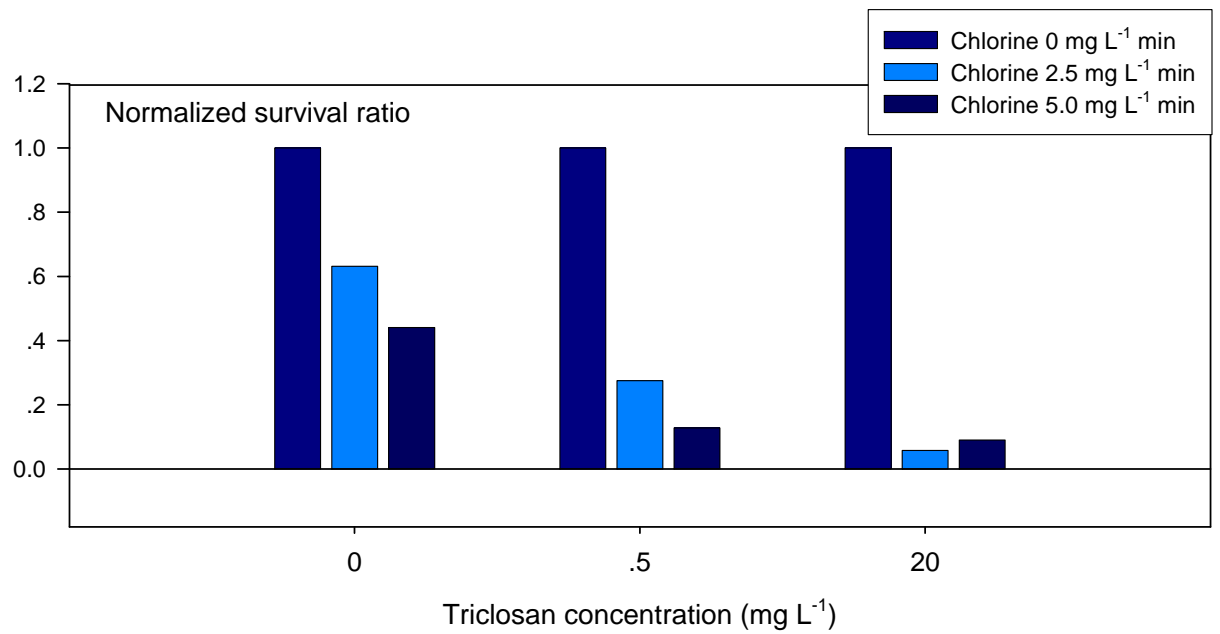

Figure 4.12: Normalized survival rates of Triclosan-acclimated activated sludge mixtures after exposure to different doses of chlorination: $0,2.5$, and $5.0 \mathrm{mg} \mathrm{L}^{-1} \mathrm{~min}$. Bacterial mixtures were acclimated in the presence of different concentrations of Triclosan (from 0 to $20 \mathrm{mg} \mathrm{L}^{-1}$ )

T-RLFP analyses were performed using DNA extracted from living cells and dead cells after sorting by flow-cytometry. 16S rDNA was amplified using universal primers and digested using 4 different restriction enzymes. DNA treated by enzyme AluI, provided the best signal and most diverse profiles and only results obtained with AluI were presented here (Figures 13, 14, and 15).

Figure 4.13 shows a significant decrease of the diversity of the bacteria community after 3 subsequent sub-cultures on synthetic sewage feed, even in the absence of Triclosan. On the other hand, as already observed previously, exposure to Triclosan resulted in further 
Chapter 4: Results and discussion

reduction of the diversity of the microbial community, as compared with the bacteria sub-cultured in the absence of Triclosan. Indeed some bacterial species appeared more represented after cultivation in the presence of Triclosan. The difference of profiles of microbial communities (Figure 4.13) shows that exposure to Triclosan induces a significant change. One may suggest that exposure to Triclosan selected Triclosan-tolerant bacteria and induced a reduction of the susceptibility of selected bacteria species rather than of the whole activated sludge community. Similarly, McBain et al. (2004) observed a general decrease of susceptibility after exposure to Triclosan.

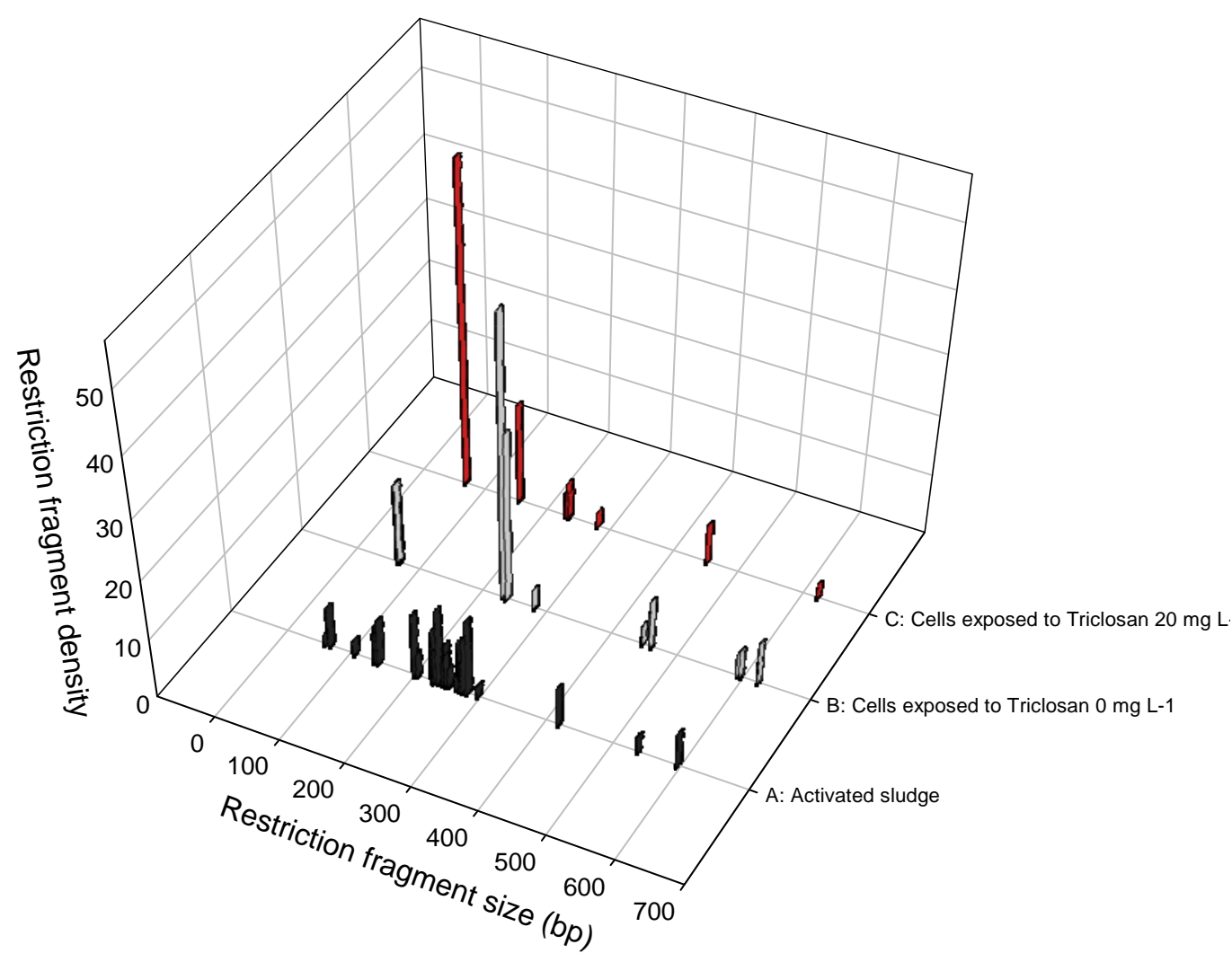

Figure 4.13: Terminal-restriction fragment profiles of bacterial communities exposed and non-exposed to Triclosan. Results are presented after normalization by the sum of the peak areas: (A) Original activated sludge bacterial community; (B) activated sludge bacterial community non-exposed to Triclosan $\left(0 \mathrm{mg} \mathrm{L}^{-1}\right)$ after three sub-cultures; (C) activated sludge bacterial community exposed to Triclosan $\left(20 \mathrm{mg} \mathrm{L}^{-1}\right)$ after three sub-cultures. 
Figure 4.14 shows that both the community structure and species profiles were significantly different for cells surviving chlorine exposure that was non-exposed and acclimated in Triclosan. The difference of profiles suggests that some bacteria species more resistance to chlorine was relatively more abundant in cultures acclimated on Triclosan.

As shown in Figure 4.14, some bacteria species alive after exposure to chlorine were present in both non-exposed and exposed to Triclosan bacteria communities. This suggest that exposure to Triclosan may select bacteria resistant to chlorination by mechanisms such as change in cellular permeability (e.g., efflux pump and adsorption). Similarly, Nagai et al. (2003) reported that $P$. fluorescens may develop both energy-dependent efflux pump systems and reduced adsorption resistance to disinfectants. 


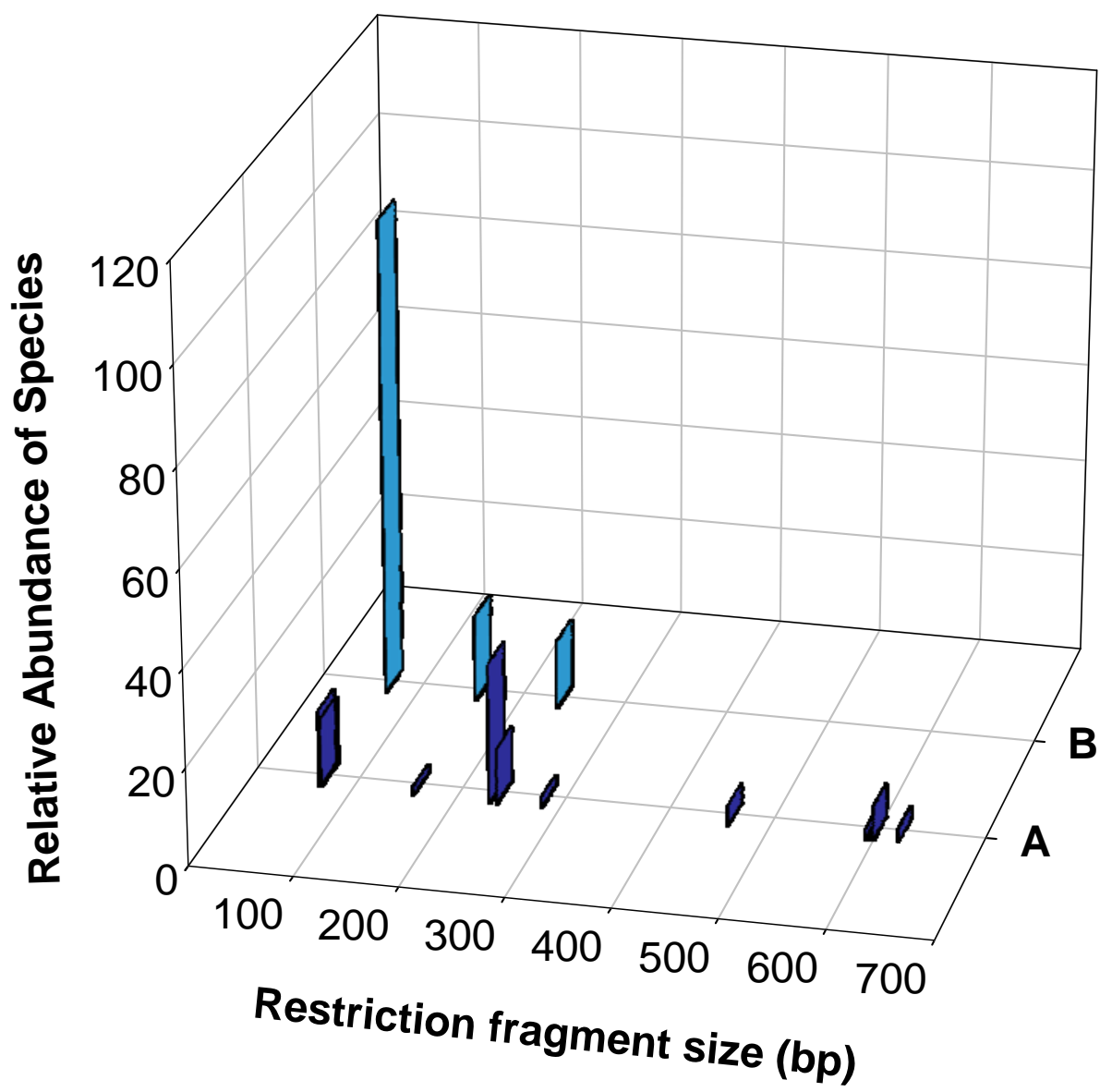

Figure 4.14: Terminal-restriction fragment profiles of bacterial communities after exposure to chlorine $2.5 \mathrm{mg} \mathrm{L}^{-1} \mathrm{~min}$. Results are presented after normalization by the sum of the peak areas: (A) Living cells non-exposed to Triclosan $\left(0 \mathrm{mg} \mathrm{L}^{-1}\right)$ after exposure to chlorine; (B) Living cells acclimated in Triclosan $\left(20 \mathrm{mg} \mathrm{L}^{-1}\right)$ after exposure to chlorine.

Figure 4.15 show that in both Triclosan-exposed and non-exposed bacterial suspensions, the profiles of dead and living cells are very similar. It is therefore suggested that chlorination affects bacteria similarly, regardless the species even after or without Triclosan exposure. These results confirm that chlorine primarily affects non-specific targets (Rusin and Gerba, 2001). 


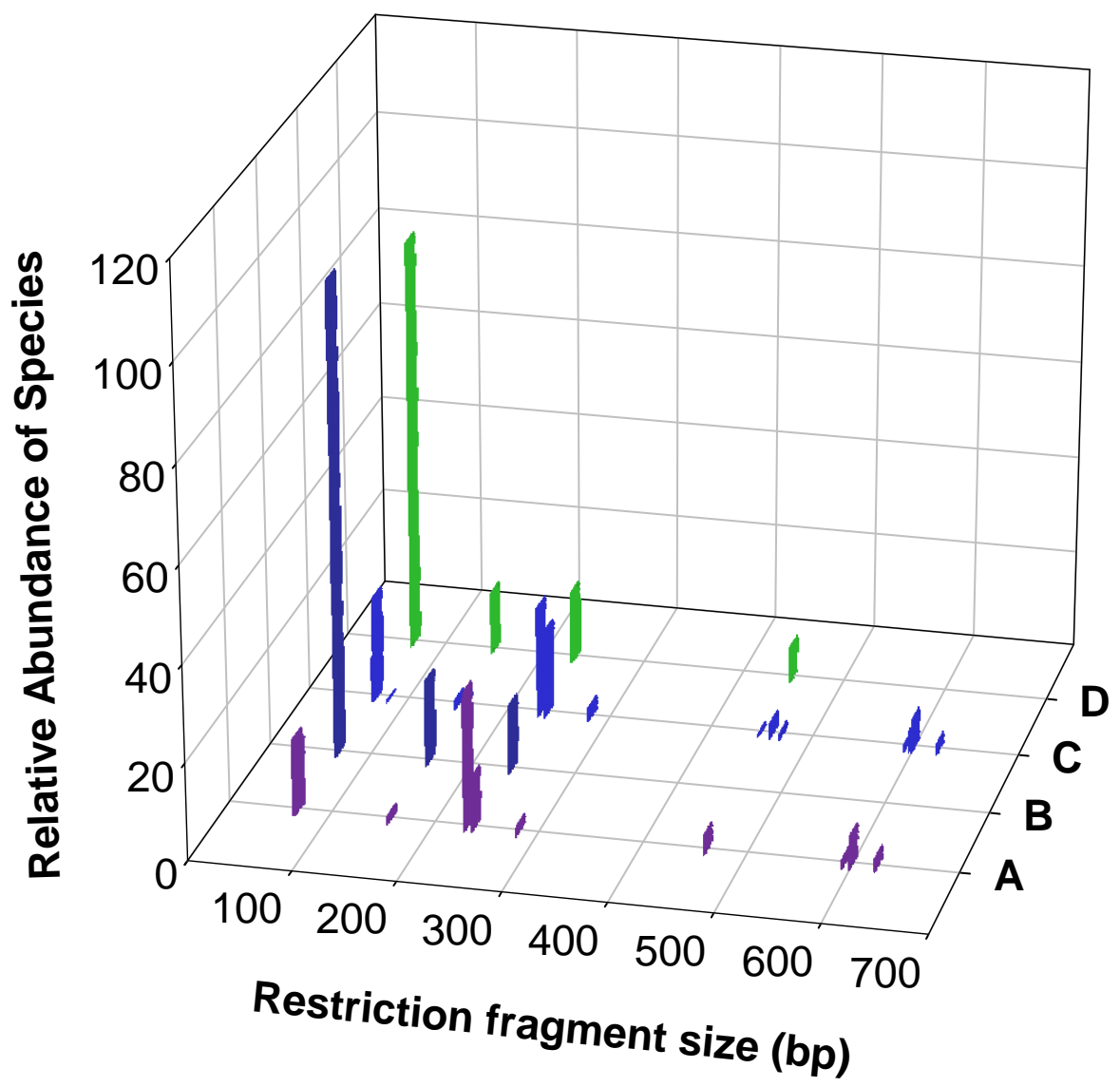

Figure 4.15: Terminal-restriction fragment profiles of bacterial communities after exposure to $2.5 \mathrm{mg} \mathrm{L}^{-1}$ min chlorine. Results are presented after normalization by the sum of the peak areas: (A) Living cells non-exposed to Triclosan $\left(0 \mathrm{mg} \mathrm{L}^{-1}\right)$; (B) dead cells non-exposed to Triclosan $\left(0 \mathrm{mg} \mathrm{L}^{-1}\right)$; (C) living cells after exposure to Triclosan $20 \mathrm{mg}$ $\mathrm{L}^{-1}$; (D) dead cells after exposure to Triclosan $20 \mathrm{mg} \mathrm{L}^{-1}$. 
Chapter 5: Conclusion

\section{Chapter 5: Conclusion:}

\subsection{Specific Aim 1}

Specific Aim 1 aimed to test the hypothesis that exposure to Triclosan would modify the susceptibility of activated sludge bacteria to chlorination and UV. In our first experiment, we observed that exposure to Triclosan induced a reduction of bacterial growth, but that exposure through successive sub-cultures resulted in a fast acclimation of bacterial communities, as shown by the reduction of the lag phase and the increase of the growth rate.

We first observed that the susceptibility of activated sludge bacteria to chlorination increased significantly after acclimation on Triclosan, which was shown to be related to a shift of the microbial community structure between exposed and non-exposed activated sludge mixtures. This phenomenon could be explained either by change of the bacterial community structure toward strains less resistant to chlorine, or by physiological changes of the bacterial cells. Chlorine could easily enter bacteria cells or damage the cell envelop, causing a leakage of proteins and DNA, which could be induced by exposure to Triclosan at high concentration. Indeed, Triclosan is suspected to modify the permeability of cells by inhibiting the cell wall building function. (Hay, 2001; Schweizer et al., 2001; Rusin and Gerba, 2001; Yazdankhah et al., 2006).

\subsection{Specific Aim 2}

In specific Aim 2, we tried to determine the origin of the change in susceptibility observed in Specific Aim 1.

\section{$\underline{\text { Sub-Aim } 1}$}

We first wanted to determine if the observed change in susceptibility to chlorination could be explained by a change in the microbial community structure after acclimation on Triclosan.

In our experiments, Triclosan exposure resulted in a significantly lower bacterial diversity 
than in non-exposed cultures. The observed change of the microbial community structure toward strains more susceptible to Chlorination could then partly explain the increase of bacterial susceptibility after acclimation on Triclosan.

\section{$\underline{\text { Sub-Aim } 2}$}

In a second step, we tried to test if exposure to Triclosan could decrease the susceptibility of highly Triclosan-resistant strains, $P$. fluorescens and S. marscecens, which were isolated from Triclosan-acclimated activated sludge bacterial mixture.

Surprisingly, P. fluorescens and S. marcescens grew well in the presence of very high concentrations of Triclosan. After acclimation on Triclosan, S. marcescens exhibited a significantly higher resistance to chlorination. It is therefore suggested that disinfection efficiency could be decreased for some pathogenic bacterial species exposed to high concentration of Triclosan, which could potentially raise a risk for human health.

Based on HPLC analysis results, we can suggest that our Triclosan-resistant isolates can reduce the concentration of Triclosan in solution, either by biodegradation or by uptake of Triclosan. Also, other resistance mechanisms, such as efflux pump system or cell adsorption may take place besides the previous mechanisms.

\subsection{Specific Aim 3}

Finally, we tried to determine the relative susceptibility to chlorination of different activated sludge members acclimated in the presence and in the absence of Triclosan. The microbial community structure was characterized by terminal-restriction fragment length polymorphism (T-RFLP) after sorting dead and living bacteria by flow-cytometry.

Triclosan acclimation changed the structure of the microbial community, possibly explaining the observed higher susceptibility to chlorination. Exposure to Triclosan induced a change of the profiles of the different microbial communities. Therefore, our hypothesis that Triclosan exposure could select tolerant bacteria and induces a reduction of the susceptibility of selected bacteria species rather than the whole activated sludge 
community appears to be acceptable. The difference of profiles between bacteria exposed and non-exposed to Triclosan suggests that exposure to Triclosan may result in higher abundance of species resistant to chlorine. It is therefore suggested that Triclosan acclimation may select bacterial resistance to chlorination.

On the other hand, regardless acclimation on Triclosan, all species seemed to be affected similarly by chlorination, supporting the previous thought that chlorine affects primarily non-specific targets (Rusin and Gerba, 2001).

Our results provide the first evidence that acclimation on sub-lethal doses of the antimicrobial agent Triclosan can result in decreasing the susceptibility of opportunistic pathogens to chlorination, which could have potential important implication for public health. In addition, our experiments combining flow-cytometry for dead-living bacteria sorting with T-RFLP for microbial community structure characterization opens the way for further research on the effect of antimicrobial agents on the relative susceptibility of different pathogens to disinfection systems.

However, besides potential negative environmental effects, Triclosan is a powerful and useful antimicrobial agent safely used for more than 30 year. Triclosan is especially useful to fight antibiotic-resistant bacteria and has significantly contributed to the improvement of public health (Swofford 2005).

The major cause for the generation of antibiotic resistance is still today recognized as the abuse of antibiotic drugs. In addition, many natural substances with antimicrobial properties, such as garlic and pine oil, could also contribute to induce antibiotic resistance (Whyte et al., 2001). 


\section{$\underline{\text { References }}$}

Anderson, D.I., 2003. Persistence of antibiotic resistant bacteria. Current Opinion in Microbiology 6, 452-456

Andrew J. McBain, Ruth G. Ledder, Louise E. Moore, Carl E. Catrenich, and Peter Gilbert, 2004. Effects of quaternary-ammonium-based formulations on bacterial community dynamics and antimicrobial susceptibility. Applied and Environmental Microbiology $70,3449-3456$

Auerbach, E.A., Seyfried, E.E. and McMahon, K.D., 2007. Tetracycline resistance genes in activated sludge wastewater treatment plants. Water Research 41, 1143-1151

Ausubel, F.M., Brent, R., Kingston, R.E., Moore, D.D., Seidman, J.G., Smith, J.A. and Struhl, K. (1999) Short Protocols in Molecular Biology, John Wiley and Sons

Benitez, M.S., Tustas, F.B., Rotenberg, D., Kleinhenz, M.D., Cardina, J., Stinner, D., Miller, S.A. and Gardener, B.B.M., 2007. Multiple statistical approaches of community fingerprint data reveal bacterial populations associated with general disease suppression arising from the application of different organic field management strategies. Soil Biology \& Biochemistry 39, 2289-2301

Cho, M., Chung, H.M. and Yoon, J., 2003. Disinfection of water containing natural organic matter by using ozone-initiated radical reactions. Applied and Environmental Microbiology 69, 2284-2291

EPA. (1996) OPPTS 850.6800 Modified Activated Sludge, Respiration Inhibition Test for Sparingly Soluble Chemicals, EPA

Fair, G. M, Morris, J. C, Chang, S. L, et al. 1948. The behavior of chlorine as a water disinfectant. J Am Water Works Assoc 40, 1051-1061

Gerhardt, P., Murray, G., Wood, W. and Krieg, N. (1994) Methods for General and Molecular Bacteriology, American Society for Microbiology

Guardabassi, L., Wong, D. and Dalsgaard, A., 2002. The effects of tertiary wastewater treatment on the prevalence of antimicrobial resistant bacteria. Water Research 36, 1955-1964

Halden, R.-U. and Paull, D.-H., Co-occurrence of triclocarban and triclosan in U.S. water resources.

Hastings, P.J., Rosenberg, S.M. and Slack, A., 2004. Antibiotic-induced lateral transfer of antibiotic resistance. Trends in Microbiology 12, 401-404

Hay, A.G., Dees, P.M. and Sayler, G.S., 2001. Growth of a bacterial consortium on triclosan. FEMS Microbiology Ecology 36, 105-112 
Hijnen, W.A.M., Beerendonk, E.F. and Medema, G.J., 2006. Inactivation credit of UV radiation for viruses, bacteria and protozoan (oo)cysts in water: A review. Water Research 40, 3-22

Hurst, C., Crawford, R., Knudsen, G., McInerney, M. and Stetzenbach, L. (2002) Manual of Enviromental Microbiology, ASM

Kolpin, D.-W., Furlong, E.-T., Meyer, M.-T., Thurman, E.-M., Zaugg, S.-D., Barber, L.-B. and Buxton, H.-T., 2002. Pharmaceuticals, hormones, and other organic wastewater contaminants in U.S. streams, 1999-2000: A national reconnaissance. Environmental Science and Technology 36, 1202-1211

Lambert, R.J, Denyer S.P, Hanlon, G.W, Johnston, M.D, 2002. Antimicrobial Synergy: A Predictable and Quantifiable Effect. Abstr Intersci Conf Antimicrob Agents Chemother Intersci Conf Antimicrob Agents Chemother 42, 27-30

Levi, S, 1997. Antibiotic Resistance: An Ecological Imbalance. In Antibiotics Resistance: Origins, Evolution, Selection, and Spread (207, C.F.S., ed.), pp. 1-14, John Wiley and Sons

Levy, S.B. and Marshall, B., 2004. Antibacterial resistance worldwide: causes, challenges and responses. Nature Medicine 10, S122-S129

Marsh, T.L., 1999. Terminal restriction fragment length polymorphism (T-RFLP): an emerging method for characterizing diversity among homologous populations of amplification products. Current Opinion in Microbiology 2, 323-327

Mason J. M, Setlow P, 1986. Essential role of small, acid-soluble spore proteins in resistance of bacillus-subtilis spores to UV-light. Journal of bacteriology Vol. 167, Issue $1,174-178$

McBain, A.J., Bartolo, R.G., Catrenich, C.E., Charbonneau, D.L., Ledder, R.G., Price, B.B. and Gilbert, P., 2003. Exposure to sink drain microcosms to Triclosan: Population Dynamics and Anitmicrobial Susceptibility. Applied and Environmental Microbiology 69, 5433-5442

Meade, M.J., Waddell, R.L. and Callahan, T.M., 2001. Soil bacteria Pseudomonas putida and Alcaligenes xylosoxidans subsp. denitrificans inactivate triclosan in liquid and solid substrates. FEMS Microbiology Letters 204, 45-48

Mezcua, M., Gomez, M.J., Ferrer, I., Aguera, A., Hernando, M.D. and Fernandez-Alba, A.R., 2004. Evidence of 2,7/2,8-dibenzodichloro-p-dioxin as a photodegradation product of triclosan in water and wastewater samples. Analytica Chimica Acta 524, $241-247$

Murphya, H.M., Paynea, S.J., Gagnon, G.A, 2008. Sequential UV- and chlorine-based disinfection to mitigate Escherichia coli in drinking water biofilms. Water Research. 42, Issues 8-9, 2083-2092 
Moretro, T., Sonerud, T., Mangelrod, E. and Langsrud, S., 2006. Evaluation of the antibacterial effect of a triclosan-containing floor used in the food industry. Journal of Food Protection 69, 627-633

Nagai, K., Murata, T., Ohta, S., Zenda, H., Ohnishi, M. and Hayashi, T., 2003. Two different mechanisms are involved in the extremely high-level benzalkonium chloride resistance of a Pseudomonas fluorescens strain. Microbiology and Immunology 47, $709-715$

National Research Council (1999). Hormonally active agents in the environment; National Academy Press: Washington, DC; $430 \mathrm{pp}$.

Neumegen, R.-A., Fernandez-Alba, A.-R. and Chisti, Y., Toxicities of triclosan, phenol, and copper sulfate in activated sludge.

Orvos, D.-R., Versteeg, D.-J., Inauen, J., Capdevielle, M., Rothenstein, A. and Cunningham, V., 2002. Aquatic toxicity of triclosan. Environmental-Toxicology-and-Chemistry 21, 1338-1349

Pumbwe, L, Ueda, O, Yoshimura, F, Chang, A, Smith, R. L, and Wexler, H, M, 2006. Bacteroides fragilis BmeABC efflux systems additively confer intrinsic antimicrobial resistance. Journal of Antimicrobial Chemotherapy 58, 37-46

Pruden, A., Pei, R.T., Storteboom, H. and Carlson, K.H., 2006. Antibiotic resistance genes as emerging contaminants: Studies in northern Colorado. Environmental Science \& Technology 40, 7445-7450

Prutz, W.A., 1996. Hypochlorous acid interactions with thiols, nucleotides, DNA, and other biological substrates. Archives of Biochemistry and Biophysics 332, 110-120

Rusin, P. and Gerba, C. (2001) Association of chlorination and UV irradiation to increasing antibiotic resistance in bacteria. In Reviews of Environmental Contamination and Toxicology, Vol 171 (Vol. 171), pp. 1-52

Russell, A.D. and Day, M.J., 1996. Antibiotic and biocide resistance in bacteria. Microbios $85,45-65$

Russell, A.D., 2003. Similarities and differences in the responses of microorganisms to biocides. Journal of Antimicrobial Chemotherapy 52, 750-763

Sambrook, J. and Russel, D.W. (2001) Molecular Cloning: A Laboratory Manual, Spring Harbor Laboratory Press

Sanchez, P., Moreno, E. and Martinez, J.L., 2005. The biocide triclosan selects Stenotrophomonas maltophilia mutants that overproduce the SmeDEF multidrug efflux pump. Antimicrobial Agents and Chemotherapy 49, 781-782 
Schwartz, T., Kohnen, W., Jansen, B. and Obst, U., 2003. Detection of antibiotic-resistant bacteria and their resistance genes in wastewater, surface water, and drinking water biofilms. Fems Microbiology Ecology 43, 325-335

Schweizer, H.P., 2001. Triclosan: a widely used biocide and its link to antibiotics. FEMS Microbiology Letters 202, 1-7

Shrivastava, R., Upreti, R.K., Jain, S.R., Prasad, K.N., Seth, P.K. and Chaturvedi, U.C., 2004. Suboptimal chlorine treatment of drinking water leads to selection of multidrug-resistant Pseudomonas aeruginosa. Ecotoxicology and Environmental Safety 58, 277-283

Sidhu, M.S., Heir, E., Leegaard, T., Wiger, K. and Holck, A., 2002. Frequency of disinfectant resistance genes and genetic linkage with beta-lactamase transposon Tn552 among clinical staphylococci. Antimicrobial Agents and Chemotherapy 46, $2797-2803$

Singer, H., Muller, S., Tixier, C. and Pillonel, L., 2002. Triclosan: Occurrence and fate of a widely used biocide in the aquatic environment: Field measurements in wastewater treatment plants, surface waters, and lake sediments. Environmental Science and Technology 36, 4998-5004

Swofford, W, 2005. Triclosan research misreported. Environmental Science, American Chemical Society \& Technology

Thies, J.E., 2007. Soil microbial community analysis using terminal restriction fragment length polymorphisms. Soil Science Society of America Journal 71, 579-591

Wilson, B.A. and Salyers, A.A., 2003. Is the evolution of bacterial pathogens an out-of-body experience? Trends in Microbiology 11, 347-350

Whyte, F.W., Allison, D.G., Jones, M.V and Gilbert, P. (2001) In vitro detection of multidrug antibiotic resistant (Mar) phenotype induction by miscellaneous groceries. Abstracts of the $104^{\text {th }}$ Meeting of the American Society for Microbiology, A99.

Woese, C., Kandler, O. and Wheelis, M., 1990. Towards a Natural System of Organisms: Proposal for the Domains Archaea, Bacteria, and Eucarya. PNAS 87, 4576-4579

Yazdankhah, S.P., Scheie, A.A., Hoiby, E.A., Lunestad, B.T., Heir, E., Fotland, T.O., Naterstad, K. and Kruse, H., 2006. Triclosan and antimicrobial resistance in bacteria: An overview. Microbial Drug Resistance-Mechanisms Epidemiology and Disease 12, $83-90$ 